\title{
Beyond the dopamine receptor: regulation and roles of serine/threonine protein phosphatases
}

\author{
Sven Ivar Walaas ${ }^{1}$, Hugh Caroll Hemmings $\mathrm{Jr}^{2,3}$, Paul Greengard ${ }^{4}$ and Angus Clark Nairn ${ }^{5}$ \\ 1 Department of Biochemistry, Institute of Basic Medical Sciences, University of Oslo, Oslo, Norway \\ ${ }^{2}$ Department of Anesthesiology, Weill Cornell Medical College, New York, NY, USA \\ ${ }^{3}$ Department of Pharmacology, Weill Cornell Medical College, New York, NY, USA \\ ${ }^{4}$ Laboratory of Molecular and Cellular Neuroscience, The Rockefeller University, New York, NY, USA \\ ${ }^{5}$ Department of Psychiatry, Yale University School of Medicine, New Haven, CT, USA
}

\section{Edited by:}

Emmanuel Valjent, Université

Montpellier 1 \& 2, France

Reviewed by:

Isabelle M. Mansuy, University of

Zurich, Switzerland

Philippe Marin, University of

Montpellier, France

*Correspondence:

Angus Clark Nairn, Department of Psychiatry, Yale University School of

Medicine, 34 Park Street, New

Haven, CT 06508, USA.

e-mail: angus.nairn@yale.edu
Dopamine plays an important modulatory role in the central nervous system, helping to control critical aspects of motor function and reward learning. Alteration in normal dopaminergic neurotransmission underlies multiple neurological diseases including schizophrenia, Huntington's disease, and Parkinson's disease. Modulation of dopamine-regulated signaling pathways is also important in the addictive actions of most drugs of abuse. Our studies over the last 30 years have focused on the molecular actions of dopamine acting on medium spiny neurons, the predominant neurons of the neostriatum. Striatum-enriched phosphoproteins, particularly dopamine and adenosine $3^{\prime}: 5^{\prime}$-monophosphate-regulated phosphoprotein of $32 \mathrm{kDa}$ (DARPP-32), regulator of calmodulin signaling (RCS), and ARPP16, mediate pleiotropic actions of dopamine. Notably, each of these proteins, either directly or indirectly, regulates the activity of one of the three major subclasses of serine/threonine protein phosphatases, PP1, PP2B, and PP2A, respectively. For example, phosphorylation of DARPP-32 at Thr34 by protein kinase A results in potent inhibition of PP1, leading to potentiation of dopaminergic signaling at multiple steps from the dopamine receptor to the nucleus. The discovery of DARPP-32 and its emergence as a critical molecular integrator of striatal signaling will be discussed, as will more recent studies that highlight novel roles for RCS and ARPP-16 in dopamine-regulated striatal signaling pathways.

Keywords: phosphorylation, protein phosphatase, protein kinase A, calcineurin, DARPP-32, ARPP-21, ARPP-16, RCS

\section{INTRODUCTION}

The neuronal circuitry of the mammalian basal ganglia (also referred to as caudate-putamen or neostriatum) is generally well understood. Major inputs in the form of glutamatergic excitatory monosynaptic inputs derive from the cerebral cortex and thalamus, with axospinous synapses terminating on the dendrites of the local cells, the vast majority of which are represented by the medium-sized spiny neurons (MSN, representing approx. 95\% of total striatal neurons), which also represent the origin of the major efferent projections. These GABAergic inhibitory striatal neurons have both dense populations of local collaterals as well as efferent striatonigral and striatopallidal GABAergic fibers terminating on local neurons in either the substantia nigra pars reticulata (the direct efferent pathway) or on local neurons in the external globus pallidus (the indirect pathway). Two major modulatory systems regulate these circuits, the most important being the nigrostriatal dopaminergic (DA) fibers originating in the pars compacta of the substantia nigra, and a less predominant serotonergic pathway originating in the raphe nuclei (Anden et al., 1966; Steinbusch, 1981; Bjorklund and Lindvall, 1984). Local intrastriatal modulations are most prominently mediated through giant cholinergic cells present within the striatum itself, which represent approximately $2 \%$ of total cell number but have major axonal connections that radiate throughout the neostriatal neuropil (Bolam et al., 1984; Zhou et al., 2002).

In addition to the classical neostriatal circuitry and cytology mentioned above, the nucleus accumbens, an adjacent brain region, was determined to represent a ventral part of the neostriatum in the 1970s. The nucleus accumbens has generally identical cellular populations and transmitters, with major glutamate inputs from hippocampus, amygdala, prefrontal cortex and thalamus, major afferent DA and serotoninergic modulatory inputs, and efferent GABAergic outputs predominantly terminating in the ventral pallidum and rostral substantia nigra (Walaas and Fonnum, 1979, 1980).

Given the role of the basal ganglia in control of motor function and reward learning, and the disruption of dopaminergic neurotransmission in diseases including schizophrenia, Huntington's disease, and Parkinson's disease, a major effort has been made to identify the molecular mechanisms that mediate and modulate neurotransmission within this brain region. Here we review aspects of DA signaling mechanisms which operate postsynaptically in MSNs, and how they serve to integrate striatal inputs. A major influence on these studies has been the characterization of phosphoproteins regulated by DA and protein kinase A (PKA) in MSNs (Nairn et al., 1985; Greengard et al., 1999; 
Svenningsson et al., 2004, 2005). In particular, the discovery of a family of substrates for PKA in MSNs has not only advanced our knowledge of dopamine-regulated signaling in the central nervous system, but has provided a framework for other signaling pathways in the nervous system, and in non-neuronal cells. Here we discuss the discovery of these proteins, and describe their roles as integrators of the multiple signaling pathways that converge on MSNs.

\section{HISTORICAL OVERVIEW OF DA SIGNALING IN STRIATAL MSNs}

Approximately 30 years ago, the existence of a DA-containing input to the caudate/putamen was generally accepted based on histofluorescence, neurochemical, and immunohistochemical studies (Bjorklund and Lindvall, 1984; Bjorklund and Dunnett, 2007; Iversen and Iversen, 2007). However, essentially nothing was known about the neurobiological mechanisms that transduced DA inputs into neurophysiological responses. Early studies demonstrated that stimulation of DA cells in the mesencephalon gave monosynaptic EPSPs in the caudate nucleus (Kitai et al., 1976), but the receptor mechanisms involved were essentially unknown. It was unlikely that DA represented a primary ionotropic neurotransmitter that directly regulated ion channel conductances. Rather, studies performed in the superior cervical ganglion (Kebabian and Greengard, 1971; Kebabian and Calne, 1979) indicated the presence in nervous tissue of DA receptors capable of generating CAMP, and more specific studies in rodent brain (Kebabian et al., 1972; Clement-Cormier et al., 1974) demonstrated that this DA receptor was indeed enriched in the neostriatum. However, the remaining cAMP cascade [cAMP-dependent protein kinase (PKA), protein substrates for this enzyme, as well as phosphoprotein phosphatases] was essentially unknown.

\section{DISCOVERY OF THE PHOSPHOPROTEIN SUBSTRATES FOR PKA IN MSNs}

A preliminary analysis of acid-soluble phosphoprotein substrates for PKA in different regions of rat brains, performed early in 1980, demonstrated that one set of widely distributed phosphoproteins (subsequently designated the synapsins) were present in all brain regions examined, but that a novel protein substrate for PKA of apparent molecular mass of $32 \mathrm{kDa}$ also was present but only in dorsal and ventral striatal regions, and essentially absent from the adjacent lateral septum or the more distant hippocampus or neocortex (Walaas and Greengard, 1984). Analysis of brain slices from the neostriatum containing intact local MSNs demonstrated that incubation with DA induced a significant increase in the state of phosphorylation of this $32 \mathrm{kDa}$ protein, which was given the name "dopamine and adenosine $3^{\prime}: 5^{\prime}$ monophosphate-regulated phosphoprotein of $32 \mathrm{kDa}$ " (DARPP32; Walaas et al., 1983a). Subsequently, characterization of this phosphoprotein was pursued in a first set of neurochemical, protein purification, and immunohistochemical studies (Hemmings Jr. et al., 1984b; Ouimet et al., 1984; Walaas and Greengard, 1984).

The success of these early studies led to a more comprehensive analysis of the anatomy of brain protein phosphorylation systems, where it became clear that the major population of region-specific PKA substrate proteins were highly enriched in the basal ganglia, particularly in the neostriatum (Walaas et al., 1983 b,c). Major striatal phosphoproteins present in addition to DARPP-32 had apparent molecular masses (as determine by SDSpolyacrylamide gel electrophoresis, SDS-PAGE) of $21 \mathrm{kDa}$ (designated ARPP-21 or regulator of calmodulin signaling, RCS, see below), $39 \mathrm{kDa}$ (Walaas and Greengard, 1993), $90 \mathrm{kDa}$ (Walaas et al., 1989); now known to be Rap1GAP (McAvoy et al., 2009), and ARPP-16 (Horiuchi et al., 1990). Further studies therefore concentrated on striatum and DA, where anatomy, disease state, neuro-, and psychopharmacological properties were reasonably well known, but where the neurobiological and physiological responses to the effects of DA mediated through protein phosphorylation were relatively unknown. Largely based on their physical properties, DARPP-32, RCS, and ARPP-16 were relatively straightforward to purify from bovine striatum, and subsequent studies have revealed that each of these proteins is highly enriched in MSNs (Figure 1) and that in different ways they serve to mediate dopamine actions through regulation of serine/threonine protein phosphatases.

\section{DARPP-32}

\section{BIOCHEMICAL PROPERTIES}

Following its identification in rat striatum as an acid-soluble phosphoprotein (Walaas et al., 1983a), DARPP-32 was purified from

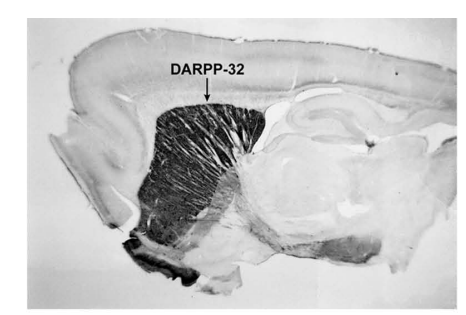

DARPP-32

Thr34

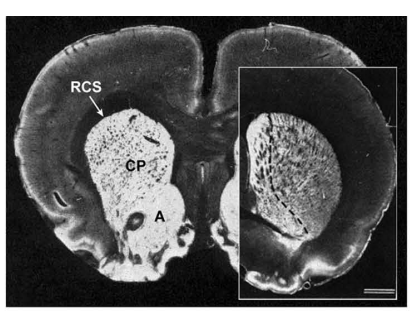

Ser55

RCS (ARPP-21)

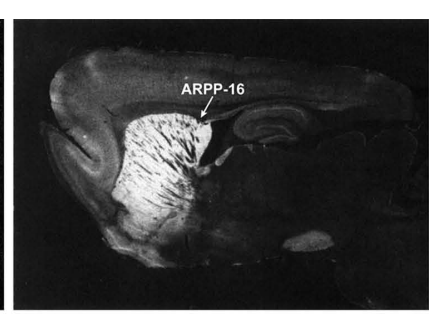

Ser88
FIGURE 1 | Localization of DARPP-32, RCS, and ARPP-16 in rat brain. DARPP-32 (left, sagittal section, positive immunoreactivity black), RCS (middle, coronal section, positive immunoreactivity white; caudate/putamen (CP), and nucleus accumbens (A); inset at right shows RCS enrichment in nucleus accumbens (left of dashed line) in more rostral section), ARPP-16 (right, sagittal section, immunoreactivity white). Simple domain diagrams of each protein with their amino acid number and site of PKA phosphorylation are shown below the respective immunolocalization panels. 
bovine caudate, based on its stability in acidic extraction conditions (Hemmings Jr. et al., 1984b). The bovine protein contains 202 amino acids with a predicted molecular weight of 22,614 (Williams et al., 1986; Kurihara et al., 1988; Figure 2). Physicochemical analysis indicated that the protein has little secondary structure and exists as an elongated monomer (Hemmings Jr. et al., 1984b). The N-terminal 40 amino acids of DARPP-32 are highly related to a corresponding region of protein phosphatase inhibitor-1, a protein originally described in skeletal muscle (Huang and Glinsmann, 1976). DARPP-32 and inhibitor-1 are phosphorylated by PKA at a conserved threonine residue (Thr34 in DARPP-32, Thr35 in inhibitor-1; note that amino acid numbering is for the mouse protein, unless otherwise indicated), with phosphorylation converting each protein into a potent inhibitor of PP1 (see further discussion below). A notable feature of the amino acid sequence of DARPP-32 is the presence of a highly acidic central region containing 24 glutamic or aspartic acid residues in a total of 32 residues. The precise function of this region is not known, although it contains a phosphorylation site for the CK2 protein kinase (Ser97), and a nuclear export sequence, that are important in control of the nucleo-cytoplasmic localization of DARPP-32 (see below). Comparison of the DARPP-32 amino acid sequence from different species indicates some heterogeneity at the C-terminus of the protein, a region that may be subject to variable phosphorylation (see below).

Fluorescence (Neyroz et al., 1993) and NMR (Lin et al., 2004; Dancheck et al., 2008; Marsh et al., 2010) spectroscopy have shown that, consistent with initial physicochemical studies, DARPP-32 has little secondary structure when studied in free solution. While the protein has all the features of a so-called "intrinsically disordered protein," there is a propensity for some $\alpha$-helical content between residues 22 and 29 located N-terminal to the PKA phosphorylation site, and between residues 92 and 109 , the region containing Ser97 and the nuclear export signal sequence (Dancheck et al., 2008; Marsh et al., 2010). Moreover, either fluorescence anisotropy or NMR studies of DARPP-32 peptides that contained paramagnetic spin labels in various positions (Dancheck et al., 2008), indicated that the central region of the protein (residues $\sim 80-115$ ) can exist as a compact core, while both the N-terminal domain including Thr34, and the C-terminus, are much more mobile. Phosphorylation by either PKA or CK2 has no marked effect on the secondary or tertiary structure of the protein.

Intrinsically disordered proteins have the ability to make extensive interactions with their interacting partners. Such disordered proteins allow multiple structural states that facilitate interactions with different binding sites at once, an important property of network hub proteins that interact with multiple binding sites and integrate signals from various pathways (Mittag et al., 2010). However, upon binding to targets like PP1, elements of DARPP32 may assume a more stable structure as has been found for inhibitor-2 and spinophilin, two other regulators of PP1 (Ragusa et al., 2010; Dancheck et al., 2011). As will be discussed below, the major target for DARPP-32 is PP1. DARPP-32 also interacts with the multiple kinases and phosphatases that regulate its phosphorylation, including PKA which it can also regulate. DARPP-32 is imported into and exported from the nucleus (see below), and a recent study has identified DARPP-32 as being able to interact with the tra2-beta1 splicing factor (Benderska et al., 2010). Therefore, DARPP-32 may have other direct protein binding partners. The intrinsically disordered feature of DARPP-32 may be critical for these various types of interaction.

\section{EXPRESSION PROFILE}

A number of detailed immunocytochemical studies have indicated that DARPP-32 is localized primarily in brain regions enriched in dopaminergic nerve terminals (Ouimet et al., 1984, 1998; Foster et al., 1987, 1988; Ouimet and Greengard, 1990). Thus, DARPP-32 is highly expressed within the caudatoputamen, nucleus accumbens, olfactory tubercle, bed nucleus of the stria terminalis, and portions of the amygdaloid complex. DARPP-32 is a cytosolic protein and immunoreactivity is present throughout neuronal cell bodies and dendrites (Ouimet et al., 1984, 1998; Ouimet and Greengard, 1990; Glausier et al., 2010). In brain regions known to receive projections from these nuclei, nerve terminals are strongly immunoreactive for DARPP-32. These target areas include the

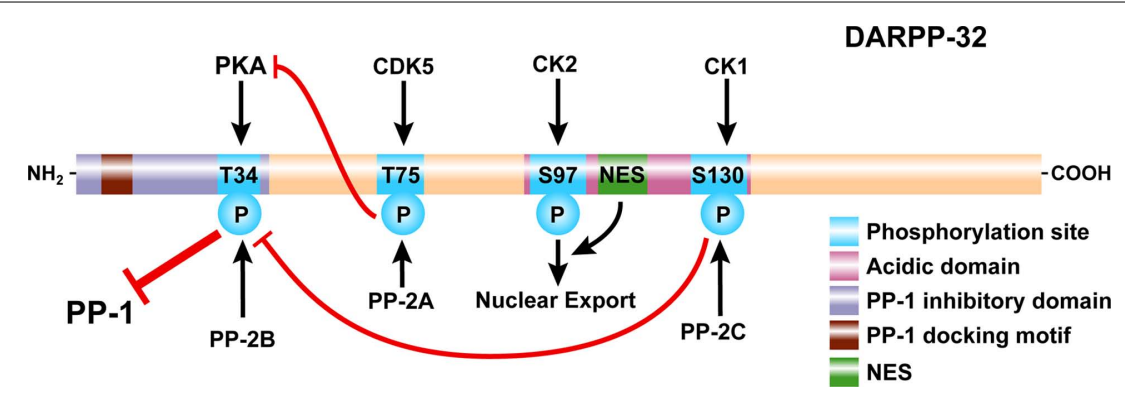

FIGURE 2 | Domain organization of DARPP-32. DARPP-32 is phosphorylated at Thr34 by PKA (and PKG, not shown), at Thr75 by Cdk5, at Ser97 by CK2, and at Ser130 by CK1. Thr34 is preferentially dephosphorylated by PP2B (calcineurin); Thr75 is preferentially dephosphorylated by PP2A; Ser97 is also preferentially dephosphorylated by PP2A (not shown); Ser130 is dephosphorylated by PP2C. Phosphorylation of Thr34 converts DARPP-32 into a potent inhibitor of PP1. A PP1 docking motif and phosphorylation of Thr34 are required for binding and inhibition of PP1. Phosphorylation of Thr75 converts DARPP-32 into an inhibitor of PKA, reducing its ability to phosphorylate DARPP-32 and other substrates. Phosphorylation of Ser130 increases phosphorylation of Thr34 through inhibition of PP2B and potentiates dopaminergic signaling via the cAMP/PKA/DARPP-32/PP-1 pathway. In contrast, phosphorylation of Thr75 acts to inhibit dopaminergic signaling via this pathway. Phosphorylation of Ser97 in conjunction with a nuclear export signal (NES) act to export DARPP-32 from the nucleus and maintain the cytoplasmic localization of the protein observed under basal conditions. 
globus pallidus, ventral pallidum, entopeduncular nucleus, and the pars reticulata of the substantia nigra (Walaas and Ouimet, 1989). No immunoreactivity is detected in neuronal cell bodies or dendrites of dopaminergic neurons. In a phylogenetic survey, DARPP-32 was identified in dopaminoceptive brain regions from representative members of the amniote vertebrate classes (birds and reptiles), while none was identified in dopaminoceptive brain regions from representative members of the anamniote vertebrate classes (bony fishes and amphibians) or in nervous tissue from representative members of several invertebrate classes (Hemmings Jr. and Greengard, 1986).

In non-striatal regions, many neurons are weakly immunoreactive for DARPP-32 and some of these are found in areas that apparently lack a dopaminergic input (Ouimet et al., 1984, 1992; Glausier et al., 2010). For example, weakly labeled neuronal cell bodies and dendrites are found throughout the neocortex, primarily in layer VI, and in the Purkinje neurons of the cerebellum. DARPP-32 immunoreactivity is also present in certain glial cells, especially in the median eminence, arcuate nucleus, and medial habenula.

\section{DARPP-32 EXPRESSION IN NON-NEURONAL CELLS/TISSUES}

While most work has focused on the function of DARPP-32 in neurons, especially in the neostriatum, DARPP-32 is also expressed in non-neuronal cells and tissues. DARPP- 32 has been identified at low levels in several peripheral tissues, including choroid plexus, parathyroid cells, adrenal chromaffin cells, posterior pituitary gland, pineal gland, and superior cervical sympathetic ganglion (Hemmings Jr. and Greengard, 1986). Several studies have elucidated a function for DARPP-32 in the kidney, where it plays a role in regulation of the $\mathrm{Na}^{+} / \mathrm{K}^{+}$-ATPase by dopamine (Meister et al., 1989; Eklof et al., 2001). DARPP-32 is expressed at high levels in the renal medulla, specifically in the thick ascending limb of Henle. DARPP-32 has also been found in brown adipose tissue from pigs (Meister et al., 1988) and cow (Stralfors et al., 1989), where it likely has the same function as inhibitor-1 which is expressed instead of DARPP-32 in adipose tissue from other mammals. In addition to the brain, DARPP-32 is also expressed in the ciliary epithelium of the eye (Stone et al., 1986), neurohypophysis, parathyroid gland (Meister et al., 1991), choroid plexus, and peripheral nervous tissues such as superior cervical ganglion and adrenal gland, most of which are associated with dopamine signaling (Hemmings Jr. and Greengard, 1986).

Unexpectedly, DARPP-32 expression has been found to be associated with a number of different cancers including gastric, adenocarcinoma, esophageal, and breast (El-Rifai et al., 2002; Ebihara et al., 2004; Varis et al., 2004). The precise role of DARPP-32 is unclear with some studies suggesting a causal role in cell proliferation, a protective role, or a role in drug resistance (Hansen et al., 2006, 2009; Hong et al., 2007). An interesting component of these studies has been the discovery of the expression of a truncated form of DARPP-32 (termed t-DARPP-32) which is missing the amino acids encoded by exon 1 (the region that contains Thr34 and inhibits phosphatase PP1 activity), and which contains an alternatively spliced exon followed by amino acids encoded by exons 2-7. t-DARPP-32 is expressed in cancer cells where it may mediate resistance to anti-cancer drugs (Belkhiri et al., 2008a,b; Gu et al., 2009; Hamel et al., 2010; Vangamudi et al., 2010).

\section{DARPP-32 PHOSPHORYLATED AT Thr34 BY PKA REGULATES PP1}

Biochemical and subsequent structure-function studies have shown that residues 5-40 of DARPP-32, in conjunction with phosphorylation of Thr34 by PKA, comprise a domain that binds to and inhibits the activity of PP1, a serine/threonine protein phosphatase that plays a major role in dephosphorylation in eukaryotic cells (Hemmings Jr. et al., 1984a, 1990; Huang et al., 1999). There are at least two sub-domains within residues 5-40 that are critical for enabling phospho-Thr34-DARPP-32 to function as a potent "pseudosubstrate-like" inhibitor of PP1 (Figure 2). A short basic/hydrophobic sequence between residues 7 and 11 (KKIQF) in DARPP-32 represents a conserved PP1 docking motif. While the exact sequence of the motif is not conserved, the basic and hydrophobic features are found in as many as 200 proteins that interact with PP1 at a conserved site in a mutually exclusive manner (Bollen et al., 2010). X-ray crystallography studies have shown that the PP1 docking motif interacts with the surface of PP1 at a position on the back of the enzyme (relative to the metalcontaining active site positioned at front center; Goldberg et al., 1995; Egloff et al., 1997). Amino acids in PP1 that interact with the basic/hydrophobic docking motif are distinct from PP2A and PP2B (calcineurin), two related serine/threonine protein phosphatases that have very similar overall structure to PP1 (Watanabe et al., 2001).

Phosphorylation of Thr34 by PKA (and also PKG) converts the protein into a potent inhibitor of PP1 with an IC50 of $\sim 1$ nM (Hemmings Jr. et al., 1984a; Huang et al., 1999). PhosphoThr34-DARPP-32 is specific for PP1, and is unable to inhibit the closely related enzymes PP2A and PP2B, or the structurally distinct PP2C. While dephospho-DARPP-32 exhibits virtually no inhibitory activity (at least $\sim 10^{6}$-fold less), the docking motif can interact with PP1 in the absence or presence of phosphorylation of Thr34 indicating the importance of cooperative two-site interaction to the high inhibitory potency (Desdouits et al., 1995a; Huang et al., 1999). DARPP-32 levels in MSNs have been estimated to be $\sim 50 \mu \mathrm{M}$ or higher (Greengard et al., 1999), and while the striatum also expresses high levels of the three PP1 isoforms found in mammalian tissues (da Cruz e Silva et al., 1995), the total concentration is likely significantly less that that of DARPP-32. Phosphorylation of Thr34 is basally low and can be stimulated $\sim 3$ - to 5-fold in response to activation of PKA (see below). Thus, even small increases in DARPP-32 phosphorylation are expected to result in substantial inhibition of PP1.

While the exact structural details of how phospho-Thr34DARPP-32 inhibits PP1 activity are not yet known, biochemical and modeling studies suggest that once docked via residues 711, phospho-Thr34 is positioned close to or in the active site, but in a conformation that is not easily dephosphorylated (Goldberg et al., 1995; Huang et al., 1997, 1999). It is possible that four arginine residues that precede Thr34, and are important for phosphorylation by PKA, interact electrostatically with residues that contribute to the acidic groove of PP1, one of three grooves (acidic, hydrophobic, and C-terminal) that emanate from the active site (Goldberg et al., 1995). However, site-directed mutagenesis has 
failed to demonstrate any significant role of the acidic side-chains within the acidic groove (Goldberg et al., 1995; Huang et al., 1997).

\section{DARPP-32 PHOSPHORYLATED AT Thr75 BY Cdk5 REGULATES PKA}

Thr75 of DARPP-32 is phosphorylated by Cdk5, a cyclindependent kinase family member, which is basally active in postmitotic neurons through association with its non-cyclin cofactor, p35 (Bibb et al., 1999). As a result, Thr75 is basally phosphorylated to a relatively high level in striatal neurons $(\sim 0.25 \mathrm{~mol} / \mathrm{mol}$; Bibb et al., 1999). Phosphorylation of Thr75 by Cdk5 has a major inhibitory effect on the phosphorylation of Thr34 by PKA. Phosphorylation of Thr75 inhibits the phosphorylation of exogenous substrates such as ARPP-16 and RCS, in vitro, supporting the hypothesis that phospho-Thr75-DARPP-32 acts generally as a PKA inhibitor. It is also possible that some of the effects of phospho-Thr75-DARPP-32 on PKA-mediated Thr34 phosphorylation result from an intramolecular effect that renders Thr34 a poorer substrate for PKA (Figure 2). As discussed in more detail below, phosphorylation of Thr75 acts in a negative feedback manner to limit the phosphorylation of Thr34 by PKA. However, this negative feedback can be relieved indirectly by PKAregulated dephosphorylation of Thr75 through a process that involves activation of PP2A by PKA (Nishi et al., 2000). Thus in many instances in intact cell preparations, there is a reciprocal relationship between the states of phosphorylation of Thr34 and Thr75.

\section{PHOSPHORYLATION OF DARPP-32 BY CK1 AND CK2}

Biochemical studies in vitro have shown that Ser97 of DARPP32 is phosphorylated by CK2, while Ser130 is phosphorylated by $\mathrm{CK} 1$, and that both of these sites are phosphorylated to high stoichiometry in vivo (Girault et al., 1989; Desdouits et al., 1995b,c). Earlier studies in vitro indicated that phosphorylation of DARPP32 at Ser97 increased the efficiency of phosphorylation of Thr34 by PKA (Girault et al., 1989). However, it is not clear if this is a major mechanism in vivo, since more recent studies have shown convincingly that phosphorylation of Ser97 by CK2 is required for nuclear export of DARPP-32, a process that ensures that under basal conditions, DARPP-32 is localized to the cytoplasm (Stipanovich et al., 2008; Figure 2; see further discussion below).

Studies both in vitro and in vivo have shown that phosphorylation of Ser130 by CK1 decreases the efficiency of dephosphorylation of Thr34 by calcineurin (PP2B), an effective phosphatase in dephosphorylating Thr34 (Hemmings Jr. et al., 1984a; King et al., 1984). Thus phosphorylation of Ser130 helps to maintain Thr34 phosphorylation levels, and thereby to potentiate dopamine/D1/PKA signaling (Figure 2; see below for further discussion).

In addition to Thr34, Thr75, Ser97, and Ser130, a mass spectrometric analysis has identified phosphorylation of either Ser45 or Ser46 and Ser192 in mouse striatum in vivo (Jin et al., 2005). Ser45/46 are probably phosphorylated by CK2 (Girault et al., 1989), although the function is not known. Ser192 is close to the C-terminus of mouse DARPP-32 and the serine and surrounding residues are not conserved in other species. The relevant kinase or the function of this phosphorylation site is also unknown.

\section{DEPHOSPHORYLATION OF DARPP-32}

Characterization of the phosphatases involved in the dephosphorylation of the various sites in DARPP-32 have also been important in revealing mechanisms that control DARPP-32 function (Svenningsson et al., 2004). Thr34 is efficiently dephosphorylated by the $\mathrm{Ca}^{2+}$-dependent phosphatase calcineurin (PP2B), which enables glutamate to negatively regulate the inhibition of PP1, and antagonize the effects of dopamine (Nishi et al., 1997, 2005). Different heterotrimeric forms of $\mathrm{PP} 2 \mathrm{~A}$ play important roles in regulation of DARPP-32 dephosphorylation (Nishi et al., 2000, 2002). PP2A containing the B56 $\delta$ subunit can be activated by phosphorylation by PKA (Ahn et al., 2007a) leading to dephosphorylation of both Thr75 and Ser97. Dephosphorylation of Thr75 relieves Cdk5-mediated inhibition of PKA and acts as an important positive feedback to stimulate Thr34 phosphorylation and inhibition of PP1 (Nishi et al., 2000). Dephosphorylation of Ser97 by PP2A plays an important role in controlling the nuclear export of DARPP-32 (Stipanovich et al., 2008). $\mathrm{Ca}^{2+}$-dependent activation of the PR72-containing heterotrimer of PP2A also plays an important role in controlling dephosphorylation of Thr75 (Ahn et al., 2007b), and possibly also Thr34 (Nishi et al., 1999, 2002) and Ser97. Finally, Ser130 dephosphorylation appears to be exclusively controlled by PP2C, where it acts as part of a phosphatase cascade whereby the level of phosphorylation of Ser130 regulates the ability of calcineurin to dephosphorylate Thr34, and hence control the level of inhibition of PP1 (Desdouits et al., 1995b,c).

\section{REGULATION OF DARPP-32 PHOSPHORYLATION}

A major effort has been made to investigate the regulation of the various phosphorylation sites in DARPP-32 in order to reveal down-stream signaling pathways of DA. An important component of these studies was the availability of phospho-specific antibodies to the four main phosphorylation sites in DARPP-32Thr34, Thr75, Ser97, and Ser137. While initial focus was on the phosphorylation of Thr34, the site that directly influences PP1 activity, a large amount of information is now known about the phosphorylation of the other sites, especially Thr75 and Ser97. Extensive studies have shown the regulation of DARPP-32 phosphorylation by neurotransmitters including dopamine, serotonin, glutamate, and GABA, as well as antipsychotic drugs and drugs of abuse (reviewed in detail by Svenningsson et al., 2004; Svenningsson et al., 2005, and in an accompanying article, Nishi et al.). Thus a key feature of DARPP-32 is to integrate the signals from diverse neurotransmitter inputs, ultimately to control the activity of PP1 and thereby its diverse down-stream targets (see below).

An important aspect of DARPP-32 regulation is the fact that the protein is expressed in all MSNs at the same level, yet it has become increasingly clear that direct and indirect pathway MSNs are functionally distinct in terms of the expression patterns of large numbers of proteins, including different DA receptor subtypes, the latter controlling opposing types of intracellular signals (Heiman et al., 2008; Valjent et al., 2009; Surmeier et al., 2010). Here we will review some recent studies of functional distinctions in DARPP-32 phosphorylation in the two principal sub-populations of striatal MSNs. 
Cell-type specific analysis of signal transduction in MSNs has been difficult to address due to the anatomical and morphological similarities of these cells. Traditional biochemical studies have the limitation that they examine a mixed population of cells and results represent only an average of signaling events. To overcome these limitations and to study DARPP-32 phosphorylation selectively in striatonigral (D1-MSNs) and striatopallidal (D2MSNs) neurons, BAC transgenic mice were generated that express both C-terminal Flag-tagged DARPP-32 under the control of the D1R promoter and C-terminal Myc-tagged DARPP-32 under the control of the D2R promoter (Bateup et al., 2008). Immunofluorescence studies confirmed the non-overlapping distribution of the two forms of tagged DARPP-32 in the D1 and D2-MSNs. Using the Flag and Myc tags, DARPP-32 from either D1R or D2Rexpressing neurons was then selectively immunoprecipitated and phosphorylation in whole animals and brain slices analyzed in a cell-type specific manner.

Cocaine blocks the dopamine transporter thereby increasing the availability of dopamine at the synapse. Using the tagged DARPP-32 mice, acute cocaine treatment was found to increase Thr34-DARPP-32 phosphorylation and decrease Thr75-DARPP-32 phosphorylation in D1-MSNs while Thr34DARPP-32 phosphorylation was decreased and Thr75-DARPP32 phosphorylation was increased in D2-MSNs. Adenosine $A_{2 A}$ receptors are highly expressed in the striatum and selectively localized to striatopallidal D2-MSNs. Acute treatment with the $\mathrm{A}_{2 \mathrm{~A}} \mathrm{R}$ antagonist caffeine increased Thr75-DARPP-32 phosphorylation in D2-MSNs with little effect on Thr34-DARPP-32 phosphorylation. Together, these results uncover important biochemical differences between D1-MSNs and D2-MSNs and demonstrate the significant advantages of using a cell-type targeted approach. It is otherwise difficult to identify opposing changes in phosphorylation in D1- and D2-MSNs which would cancel each other out in whole tissue homogenates.

\section{DOWN-STREAM TARGETS FOR DARPP-32/PP1}

As a result of the pleiotropic actions of PP1 on many cellular substrates, DARPP-32 is able to control diverse down-stream targets that range from ion channels and ligand-gated neurotransmitter receptors, to intracellular signaling cascades that control gene transcription. These in turn are coupled to long-term alterations in synaptic plasticity, and ultimately to control of behavior (see detailed reviews in Svenningsson et al., 2004, 2005). Initial studies of DARPP-32 function relied on biochemical approaches, but the availability of DARPP-32 knockout mice (Fienberg et al., 1998), and more recently "knockin" mice in which single phosphorylation sites were mutated to alanine (Svenningsson et al., 2003; Valjent et al., 2005; Zachariou et al., 2006; Zhang et al., 2006; Borgkvist et al., 2007; Stipanovich et al., 2008; BertranGonzalez et al., 2009), has directly established a critical role for DARPP-32 in neuronal function. DARPP-32 is required for normal responses to dopamine, as well as for the actions of drugs that influence dopamine function, including antipsychotic drugs and many drugs of abuse. DARPP-32 is also required for the actions of other neurotransmitters such as serotonin (Svenningsson et al., 2002a,b, 2003) or adenosine (Lindskog et al., 2002).
As an example of these studies, an important role for DARPP32 has been found in the regulation of activity of the extracellular signal-regulated kinase (ERK), an enzyme that is critical for longterm synaptic plasticity in MSNs (Valjent et al., 2005). Many drugs of abuse exert their addictive effects by increasing extracellular DA in the nucleus accumbens, where they likely alter the plasticity of corticostriatal glutamatergic transmission. In particular, psychostimulant drugs and other drugs of abuse activate ERK in D1-MSNs in dorsal and ventral striatum, through the combined action of glutamate NMDA and D1-dopamine receptors. Notably, activation of ERK by various drugs, including $\mathrm{D}$-amphetamine, cocaine, nicotine, morphine, or $\Delta 9$-tetrahydrocannabinol, was attenuated in DARPP-32 null mice. Moreover, the effects of D-amphetamine or cocaine on ERK activation in the striatum were prevented in knockin mice in which Thr34 was mutated to alanine. Regulation by DARPP-32 was found to occur at multiple levels, both upstream of ERK and at the level of striatal-enriched tyrosine phosphatase (STEP). Altered behavioral responses to psychostimulants were also prevented in the DARPP-32 mutant mice. Thus, activation of ERK, via a multi-level control of protein phosphatases, functions to integrate the coincident action of dopamine and glutamate converging on MSNs, and is critical for long-lasting effects of drugs of abuse.

While most studies have focused on the biochemical actions of DARPP-32 and behavioral consequences in the dorsal and ventral striatum, DARPP-32 also plays a role in other brain regions including cortex, hippocampus, and hypothalamus. For example, in hippocampus and cortex, DARPP-32 phosphorylation is regulated by serotonin, and biochemical and behavioral studies with DARPP32 knockout mice implicate DARPP-32 in the actions of serotonin and anti-depressant drugs (Svenningsson et al., 2002a,b). In hypothalamus, Thr34 of DARPP-32 is phosphorylated in response to progesterone, and the actions of progesterone on sexual receptivity were attenuated in DARPP-32 knockout mice (Mani et al., 2000). Recent genetic studies also implicate DARPP-32 in prefrontal cortical processes linked to general intelligence, learning, and cognition (Frank et al., 2007, 2009; Kolata et al., 2010; Doll et al., 2011; Frank and Fossella, 2011). Other studies have shown a role for DARPP-32 in non-neuronal cells and tissues (see above).

As discussed above, DARPP-32 is found in all MSNs, where its phosphorylation is differentially controlled by the selective expression of different neurotransmitter receptors, including D1 and D2 dopamine receptors (Svenningsson et al., 2004). To address the specific role of DARPP-32 in different sub-populations of MSNs, studies have been carried out recently to selectively knockout the protein in either striatonigral (D1-MSNs) or striatopallidal (D2-MSNs) medium spiny neurons (Bateup et al., 2010). Loss of DARPP-32 in D1-MSNs decreased both basal and cocaineinduced locomotion and also abolished dyskinetic behaviors in response to L-DOPA, a drug used to treat Parkinson's disease. Loss of DARPP-32 in D2-MSNs increased locomotor activity and strongly reduced the cataleptic response to the antipsychotic drug haloperidol. Interestingly, LTP was disrupted in both D1- and D2-MSNs. These results highlight the selective contributions of DARPP-32 in different MSN populations, and reinforce the need for highly specific control of gene expression when carrying out 
functional analysis of proteins in the striatum or other parts of the central nervous system.

\section{REGULATION OF NUCLEAR TRAFFICKING OF DARPP-32}

As discussed above, signaling pathways important for the transcriptional effects of dopamine involve PKA and ERK, and clearly also involve DARPP-32. However, the precise mechanisms of the transfer of information from the cytoplasm to the nucleus of striatal neurons are still poorly characterized. Recent studies have found that phosphorylation/dephosphorylation of Ser97 of DARPP-32 is crucial for control of the nucleo-cytoplasmic distribution of DARPP-32 (Stipanovich et al., 2008; see also accompanying article by Girault et al., for further details). As mentioned above, previous studies of DARPP-32 had suggested it to be largely a cytoplasmic protein, regulating the phosphorylation state of cytoplasmic or plasma membrane-associated targets. However, some earlier studies hinted that the protein might also be present in the nucleus (Ouimet and Greengard, 1990). Immunohistochemical studies led to the observation that Thr34-phospho-DARPP-32 immunoreactivity was strong in the nuclei of mice treated acutely with cocaine, D-amphetamine, or morphine, and this was confirmed with an antibody that recognized total DARPP-32. Subsequent biochemical studies of DARPP-32 in culture and using mice bearing a Ser97Ala point mutation identified a nuclear export motif adjacent to Ser97 that was controlled by phosphorylation of Ser97 (Figure 2). Ser97 of DARPP-32 is phosphorylated to high levels under typical basal conditions in vivo. Nuclear accumulation was found to be mediated through a signaling cascade involving dopamine D1 receptors and cAMP-dependent activation of a specific heterotrimeric form of protein phosphatase PP2A that acts to dephosphorylate DARPP-32 at Ser97, leading to inhibition of its nuclear export. Other studies have clarified the mechanism of activation of PP2A by PKA, which involves phosphorylation of the B56 $\delta$ subunit of the PP2A heterotrimer (Ahn et al., 2007a).

Further studies by Stipanovich et al. (2008) showed that translocation of the active phospho-Thr34-DARPP-32 to the nucleus was accompanied by inhibition of nuclear PP1 and marked stimulation of the phosphorylation level of Ser10 of histone H3, a key component of the nucleosomal response. Notably, drugs of abuse, as well as food reinforcement learning, promote nuclear accumulation of DARPP-32, but this did not occur in mice expressing Ser97Ala-DARPP-32, which remained preferentially nuclear. Moreover, behavioral studies in mice indicated that mutation of Ser97 profoundly altered a number of responses to drugs of abuse, emphasizing the functional importance of this signaling cascade.

\section{MODELING OF DARPP-32/PP1 SIGNAL TRANSDUCTION}

The extensive studies of DARPP-32-dependent signaling have provided significant insight into modes of signal transduction machinery used by neurons to provide a coordinated set of appropriate physiological responses to multiple diverse stimuli including neurotransmitters or drugs of abuse. In a broader context, a large proportion of studies in the biological sciences are now devoted to elucidating such signaling pathways, which are far more complex than had been anticipated and for which it is often impossible to intuitively gage the relative importance of the different components involved. As a result, alternative approaches including mathematical modeling are necessary to understand the functions of these complex signaling pathways. In this regard, several recent studies have been carried out that use the DARPP-32/PP1 signaling network as a model (Fernandez et al., 2006; Barbano et al., 2007; Lindskog, 2008; Nakano et al., 2010). While the models employ different components and use different approaches, a number of common features emerge. As more details emerge of the DARPP-32 network, these approaches are likely to become more important, and be predictive of the in vivo state of striatal neuron signaling.

In one study, a mathematical tool was developed that can elucidate biological network properties by analyzing global features of the network dynamics without relying on detailed information about the concentrations of signaling components or rate constants for the reaction pathways that link these components (Barbano et al., 2007). The conclusions from this study were that the network topology appears to serve to stabilize the net state of DARPP-32 phosphorylation in response to variation of the input levels of the neurotransmitters dopamine and glutamate, despite significant perturbation to the concentrations and levels of activity of the intermediate chemical species. A notable component of the stability of the DARPP-32 network was the positiveand negative-feedback modulatory phosphorylation pathways of DARPP-32 involving CK1, CK2, and Cdk5.

Two other studies modeled overlapping components of the DARPP-32 network, but attempted to estimate component concentrations and rate constants based on experimental data (Fernandez et al., 2006; Lindskog, 2008). In particular the study by Fernandez and colleagues presented a comprehensive number of parameters, and incorporated three of the four phosphorylation sites in DARPP-32 (Thr34, Thr75, and Ser130), whereas the Lindskog model was more limited in the number of components and incorporated only Thr34 and Thr75. Notably, the Fernandez model confirmed an important role of Cdk5 and Thr75 phosphorylation, but suggested less of a role for PKA-dependent activation of PP2A. The model also analyzed the pattern of inputs from calcium and cAMP, and investigated the effects of mutation of the key phosphorylation sites in silico. The Lindskog model also emphasized the important role of phosphorylation of Thr75 by Cdk5, its role in inhibiting PKA and the dephosphorylation of Thr75 by PP2A following activation of PKA.

In a more recent study, elements of the DARPP-32 network have been incorporated into a model of synaptic plasticity in a dendritic spine from a MSN (Nakano et al., 2010). The model includes inputs from NMDA, AMPA and mGluR glutamate receptors, dopamine D1 receptors, and voltage-gated $\mathrm{Ca}^{2+}$ channels, with the output being AMPA receptor trafficking to the post-synaptic membrane. This model included DARPP-32 phosphorylated at Thr34, Thr75, and Ser130, and also relied largely on experimentally derived parameters. In contrast to the Fernandez et al. (2006) study, the study by Nakano and colleagues demonstrated a robust bi-stable behavior for the PKA/PP2A/Thr75 element of the model, and suggested that this could play an important role in the switch between longterm potentiation and long-term depression in striatal neurons. Together these models provide viable hypotheses for experimental testing. 


\section{DARPP-32 AND SCHIZOPHRENIA/DISEASE}

The critical role of DARPP-32 in integrating dopaminergic, serotonergic, and glutamatergic signaling in dopaminoceptive neurons has suggested the possible involvement of DARPP-32 in the pathophysiology of neuropsychiatric diseases. A potential role for DARPP-32 signaling in psychogenesis was demonstrated using a mouse model of schizophrenia and mutations affecting DARPP-32 signaling. Phosphorylation of DARPP-32 by and behavioral responses to diverse psychotomimetics were strongly attenuated in mice with genetic deletion of DARPP- 32 or with specific phospho-null mutations in the phosphorylation sites Thr34, Thr75, and Ser 130 (Svenningsson et al., 2003). This study showed that phosphorylation of DARPP-32 at multiple sites involved in its regulation of PP1 and PKA signaling is increased by psychotomimetic drugs that target dopaminergic (amphetamine), serotonergic (LSD), and glutamatergic (ketamine) signaling, and that phosphorylation of DARPP-32 is crucial to their behavioral actions.

In human studies, biochemical and neuropathological evidence has implicated altered DARPP-32 function in both the positive (psychotic) and negative (cognitive dysfunction) symptoms of schizophrenia. DARPP-32 protein levels were reduced in postmortem samples of dorsolateral prefrontal cortex obtained from 14 schizophrenic subjects compared to matched controls (Albert et al., 2002). This brain region that has been implicated in the prefrontal cognitive-affective dysfunction observed in schizophrenia, and signaling in this area is subject to dopaminergic and serotonergic modulation. Control experiments showed that this effect was specific for DARPP-32 compared to two synaptic phosphoproteins and was not secondary to neuroleptic drug use. An independent study reported reduction in DARPP-32 protein expression detected by immunoblotting and immunocytochemistry in postmortem dorsolateral prefrontal cortex samples from schizophrenic and bipolar patients compared to controls (Ishikawa et al., 2007). Reduced DARPP-32-immunoreactive cell density has been found in postmortem samples of the superior temporal gyrus from schizophrenic patients, a brain region associated with structural and functional abnormalities in schizophrenia (Kunii et al., 2011). In a small flow cytometric analysis of DARPP-32 expression in peripheral immune cells, reduced levels of DARPP-32 were detected in CD4+ T lymphocytes and CD56+ NK cells isolated from schizophrenic patients compared to controls (Torres et al., 2009). In contrast, analysis by real time PCR of the expression of 17 genes associated with dopamine signaling in dorsolateral prefrontal cortex samples found increased DARPP-32 expression in patients with schizophrenia or bipolar disorder compared to matched controls (Zhan et al., 2011).

Analysis of DARPP-32 mRNA expression by in situ hybridization found no change in postmortem dorsolateral prefrontal or anterior cingulate cortex (Baracskay et al., 2006) or thalamus (Clinton et al., 2005) samples from schizophrenic patients compared to controls. This suggests that changes in protein expression are translational or post-translation rather than transcriptional. However a small underpowered study reported preliminary evidence for reduced DARPP-32 mRNA expression and differences in single nucleotide polymorphisms (SNPs) in postmortem prefrontal cortex samples between schizophrenic patients who died by suicide compared to those who died from other causes (Feldcamp et al., 2008). Studies in rodents have confirmed that neuroleptic medications do not affect DARPP-32 protein or mRNA levels (Grebb et al., 1990; Baracskay et al., 2006; Souza et al., 2008).

A systematic search for mutations in the DARPP-32 gene $(P P 1 R 1 B)$ in Chinese schizophrenic patients identified a number of coding and non-coding mutations. However follow-up SNP and haplotype studies of additional schizophrenic patients and controls showed no association of any of the variants with the disease (Li et al., 2006). An analysis of five different SNPs in the PP1R1B gene of 520 Chinese schizophrenic patients and 320 controls (Hu et al., 2007), as well as a similar analysis of four SNPs in 384 Japanese schizophrenic subjects and 384 controls (Yoshimi et al., 2008), found no association of any of the variants with the disease. However a traditional genetic approach involving sequencing of the $P P 1 R 1 B$ gene in postmortem human brain from white and African American subjects identified common non-coding single nucleotide variants, mostly within a seven SNP haplotype, that were associated with differences in mRNA expression, and neostriatal volume, activation and functional connectivity with the prefrontal cortex (Meyer-Lindenberg et al., 2007). Moreover, the haplotype was associated with a risk for schizophrenia in a preliminary family based association study. Interestingly, the PP1R $1 B$ gene is located at $17 \mathrm{q} 12$, near a region implicated in the risk for development of schizophrenia (Lewis et al., 2003).

In summary, although there are some inconsistent findings, studies have reported reductions in DARPP-32 protein expression in human brain regions associated with schizophrenic pathology. This change is not correlated with reduced mRNA expression or specific genetic mutations, and is not associated with neuroleptic treatment. It is most likely due to effects of the disease on protein translation or post-translational modification of DARPP-32, or to selective neuron loss. Further studies will be required to determine the mechanisms involved, the functional implications, and the potential for therapeutic intervention.

\section{ARPP-21 (RCS) BIOCHEMICAL PROPERTIES}

Regulator of calmodulin signaling (RCS) is a small, heat-stable, acidic protein of 88 residues, with a calculated molecular mass of 9561 for the bovine protein (Hemmings Jr. and Greengard, 1989; Williams et al., 1989). RCS is phosphorylated by PKA at a single serine residue (Ser55, Figure 1; Hemmings Jr. et al., 1989). To date no other phosphorylation sites have been identified. Studies using striatal slices have found that Ser55 of RCS is phosphorylated in response to activation of PKA by D1 receptor agonists, while activation of D2 receptors leads to decreased phosphorylation (Tsou et al., 1993; Caporaso et al., 2000). Moreover, exposure of mice to the psychostimulants methamphetamine or cocaine also increased Ser55 phosphorylation (Caporaso et al., 2000). In vitro, phosphoRCS is effectively dephosphorylated by PP1 and PP2A, but not by PP2B or PP2C (Hemmings Jr. and Greengard, 1989), but studies using DARPP-32 knockout mice suggest little involvement of PP1 in vivo (Caporaso et al., 2000).

The protein is predicted to have little secondary or tertiary structure, and like DARPP-32 and ARPP-16, is likely to be an intrinsically disordered protein. The amino acid sequence gives 
no insight into its potential function, and RCS has no similarity to any other protein except for a thymocyte-specific variant, termed thymus-specific cyclic AMP-regulated phosphoprotein (TARPP), that is alternatively spliced from the RCS gene (Kisielow et al., 2001). TARPP protein is highly expressed in immature thymocytes, where it may have a role in thymocyte development. However, TARPP is expressed at very low levels in brain.

\section{EXPRESSION PROFILE}

Extensive immunocytochemical analysis has shown that within the basal ganglia, DARPP-32, RCS, and ARPP-16 are all highly expressed in the MSNs that are the targets for mesolimbic and nigrostriatal dopamine systems (Ouimet et al., 1984, 1989; Girault et al., 1990; Figure 1). While DARPP-32, RCS, and ARPP-16 are all enriched in these brain regions, the precise localizations of these proteins are not identical. Studies in rat have revealed that RCS immunostaining is more intense in the nucleus accumbens than in the caudatoputamen (Ouimet et al., 1989). RCS, like DARPP32 and ARPP-16, is a cytoplasmic protein that does not appear to be enriched in any particular sub-cellular compartment. Within the caudatoputamen, RCS immunoreactivity is strongest in the medial portion of rostral sections of the nucleus accumbens. In contrast to DARPP-32, for which most MSNs in the striatum were immunoreactive, RCS staining was not present in all MSNs. The distribution of DARPP-32 and RCS are also distinct in cortical regions, including the frontal cortex where RCS is found in layers I and II, whereas DARPP-32 is more concentrated in deeper layers. Thus, RCS and DARPP-32 may subserve overlapping but distinct roles in signal transduction processes that are specific to one or another population of neurons present within different regions of the basal ganglia.

\section{REGULATION OF CALMODULIN BY RCS}

A yeast two-hybrid system, used to study potential proteinprotein interactions, identified the ubiquitous $\mathrm{Ca}^{2+}$-binding protein calmodulin (CaM) as a binding partner for ARPP-21 (Rakhilin et al., 2004). The interaction between ARPP-21 and CaM was confirmed using a variety of biochemical approaches. Notably, phosphorylation of ARPP-21 by PKA resulted in increased affinity of the protein for CaM. Phosphorylated, but not dephosphorylated, ARPP-21 effectively inhibited the activities of the CaM-dependent protein phosphatase, calcineurin, and a CaM kinase (CaMKI). The inhibitory activity of phospho-RCS appears to result from sequestration of CaM, thereby preventing CaM binding to these targets. Although CaM is expressed in very high concentrations in most cell types (possibly $>100 \mu \mathrm{M}$ ), the level of CaM is significantly lower than that of all of its targets. Thus the amount of free CaM is limited and phosphorylation of RCS would be expected to influence CaM-dependent signaling by regulating its availability. Based on these properties, ARPP-21 was renamed RCS.

As mentioned above, in MSNs, calcineurin plays a critical role in dephosphorylation of Thr34 of DARPP-32. For example, in striatal slices D2-receptor agonists activate calcineurin leading to dephosphorylation of Thr34 of DARPP-32 (Nishi et al., 1999). Consistent with the role of RCS to suppress calcineurin activity, the effect of the D2-receptor agonist, quinpirole, on Thr34 dephosphorylation, was greater in striatal neurons from RCS knockout mice (Rakhilin et al., 2004).

Previous studies had found that calcineurin is a potent regulator of L-type $\mathrm{Ca}^{2+}$ channels in MSNs (Hernandez-Lopez et al., 2000). Mobilization of intracellular $\mathrm{Ca}^{2+}$ stores by activation of either D2 dopaminergic or M1 muscarinic receptors leads to activation of calcineurin and suppression of L-type $\mathrm{Ca}^{2+}$ channel currents. Following on from this earlier work, studies using neurons from RCS knockout mice showed that the protein plays an important role in modulation of L-type $\mathrm{Ca}^{2+}$ current by $\mathrm{D} 2$ dopaminergic or by M1 muscarinic receptors through its PKA-mediated suppression of calcineurin (Rakhilin et al., 2004).

\section{ROLE OF RCS IN TRANSCRIPTIONAL CONTROL BY MEF2}

The myocyte enhancer factor 2 (MEF2) transcription factor has been found to play an important role in the behavioral responses to repeated cocaine administration, and to be also involved in the effects of this psychostimulant on the dendritic spine morphology of MSNs in nucleus accumbens and dorsal striatum (Flavell et al., 2006; Shalizi et al., 2006). MEF2 activity is stimulated by glutamatergic synaptic activity, which increases $\mathrm{Ca}^{2+}$ influx via L-type voltage-sensitive $\mathrm{Ca}^{2+}$ channels (LT-VSCCs) and activation of $\mathrm{Ca}^{2+} /$ calmodulin $\left(\mathrm{Ca}^{2+} / \mathrm{CaM}\right)$-dependent signaling pathways. $\mathrm{Ca}^{2+} / \mathrm{CaM}$ then stimulates calcineurin to dephosphorylate MEF2, including two inhibitory Cdk5 sites, to promote MEF2 activation. Recent studies showed that cocaine suppresses striatal MEF2 activity in part through a mechanism involving cAMP, RCS, and calcineurin (Pulipparacharuvil et al., 2008). Reduced MEF2 activity in the nucleus accumbens in vivo was found to be required for the cocaine-induced increases in dendritic spine density. Surprisingly, increased MEF2 activity in the accumbens, which blocked the cocaine-induced increase in dendritic spine density, enhanced sensitized behavioral responses to cocaine. Together, these findings implicate MEF2 as a key regulator of structural synapse plasticity and sensitized responses to cocaine and suggest that reducing MEF2 activity (and increasing spine density) in the nucleus accumbens may be a compensatory mechanism to limit long-lasting maladaptive behavioral responses to cocaine. The fact that RCS plays a role in the regulation of MEF2 dephosphorylation suggests that it likely is involved in the processes whereby psychostimulants can increase spine density in MSNs.

\section{FUNCTIONAL ROLE OF RCS IN ANXIETY AND MOTIVATION}

Regulator of calmodulin signaling expression is high in the dorsal striatum, nucleus accumbens, and amygdala, suggesting that the protein is involved in limbic-striatal function. RCS knockout mice have been recently created and examined in terms of behavioral models dependent on these brain areas (Davis et al., in revision). While RCS knockout mice showed normal acquisition of a food-motivated instrumental response, they exhibited a lower breakpoint when tested on responding on a progressive ratio schedule of reinforcement. Moreover, RCS knockout mice displayed decreased exploration in both the open arms of an elevated plus maze and in the center region of an open field, suggesting an enhanced anxiety response. Notably, biochemical studies revealed a reduction in the levels of DARPP-32 and of the 
GluR1 glutamate receptor in the striatum of the knockout mice. As DARPP-32 and GluR1 are important in the acquisition and maintenance of reward-mediated behavior, the altered expression of these proteins might be involved in the behavioral deficits found in RCS knockout mice.

\section{ROLE OF RCS IN STRIATAL SIGNALING}

By binding CaM and inhibiting calcineurin, phospho-RCS has the ability to amplify signaling mediated by D1-dopamine receptors and other PKA-mediated GPCRs, and to attenuate signaling mediated by competing D2 dopamine receptors, M1 muscarinic receptors and other PLC-activating GPCRs. The ability of phospho-RCS to inhibit calcineurin is analogous to that of phospho-DARPP-32 to inhibit PP1. Working in concert, these two signal transduction mechanisms serve to amplify the cellular consequences of PKA activation in MSNs (Figure 3). Notably, through its ability to control the dephosphorylation of Thr34 of DARPP-32 by calcineurin, the actions of RCS may in part be mediated through its ability to regulate DARPP-32 signaling (Figure 3). The observation that DARPP-32 expression is reduced in striatum in RCS knockout mice, further supports the view that RCS function may in part be dependent on DARPP-32. Altogether the various results indicate that RCS plays an important role in integration of key neurotransmitter inputs into MSNs, placing it in a potentially pivotal position to regulate striatal function in health and disease through binding to $\mathrm{CaM}$ and affecting the activation of multiple CaM targets, particularly calcineurin.

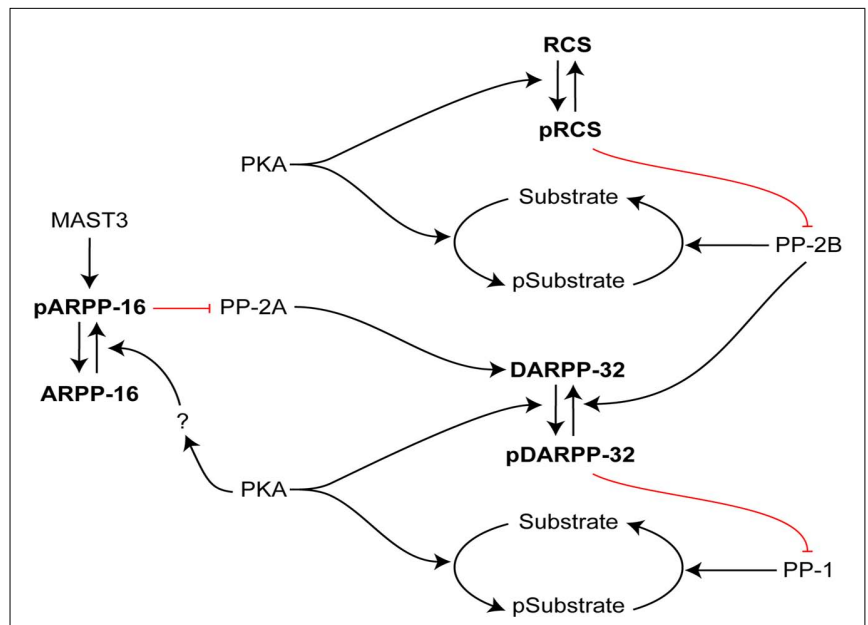

FIGURE 3 | Interactive roles of DARPP-32, RCS, and ARPP-16 in regulation of signal transduction in striatal MSNs. The efficacy of phosphorylation by PKA of numerous PKA/PP1 substrates is increased by PKA phosphorylation of DARPP-32, which inhibits PP1. In an analogous manner, the efficacy of phosphorylation by PKA of numerous PKA/PP2B substrates is increased by PKA phosphorylation of RCS, which inhibits PP2B. In contrast, ARPP-16 appears to be basally phosphorylated by MAST3 kinase, leading to inhibition of the action of PP2A on selective substrates including Thr75 of DARPP-32 (a site that acts basally to attenuate PKA's ability to phosphorylate Thr34 of DARPP-32; not shown, see Figure 2). PKA may modulate the ability of MAST to phosphorylate ARPP-16 or influence the effect of ARPP-16 on PP2A. RCS and ARPP-16 in different ways may act to control DARPP-32's ability to inhibit PP1.

\section{ARPP-16}

\section{BIOCHEMICAL PROPERTIES}

Initial biochemical studies indicated that ARPP-16 and a related protein, ARPP-19, are very basic, heat- and acid-stable monomers without known enzymatic activity (Horiuchi et al., 1990). The molecular weights predicted from cDNA cloning (10,653 and $12,353 \mathrm{Da}$, respectively for the bovine proteins) are significantly lower than their respective SDS-PAGE mobility ( 16 and $19 \mathrm{kDa})$. Thus like DARPP-32 and RCS, this is indicative of elongated asymmetric structure, although notably ARPP-16 migrates with an apparent molecular weight that is smaller than RCS, yet the protein is slightly longer in terms of amino acid content (Figure 1). As with DARPP-32 and RCS, this combination of biochemical properties is common for small non-enzymatic intracellular regulatory proteins. NMR studies have confirmed that ARPP-19 (and by implication ARPP-16) are intrinsically unstructured proteins (Huang et al., 2001).

Based on comparison of amino acid sequences, ARPP-16 and ARPP-19 are members of an evolutionarily conserved protein family with multiple isoforms (Dulubova et al., 2001; Figure 4). ARPP-16 and ARPP-19 are derived from the same gene by alternative splicing, with ARPP-19 having an additional 16 amino acids at its N-terminus. The amino acid sequences of ARPP-16 and ARPP19 are remarkably conserved in various species including human, bovine, and rodents, although frog and chicken ARPP-19 contain a few differences. ARPP-19 is closely related to alpha-endosulfine (or ENSA), a protein originally identified as a putative endogenous ligand of the sulfonylurea receptor (Heron et al., 1998; see below). In addition, open reading frames predicted from genomic or EST sequences suggest the existence of other ARPP-16/19 homologs. One of these is more closely related to ENSA, and may be a splice variant of the ENSA gene.

ARPP-16 and ARPP-19 are encoded by three exons. Exon 1 (13.4 $\mathrm{kb}$ upstream) encodes the $\mathrm{N}$-terminal extension found in ARPP-19, while the other two exons encode ARPP-16. The ARPP$16 / 19$ gene is located on Chr15 (in human). There is a sequence related to that of ARPP-16/19 on Chr5 but this may be a pseudogene since it is not spliced, and though very similar in DNA sequence, is not identical to the Chr15 sequences, and encodes

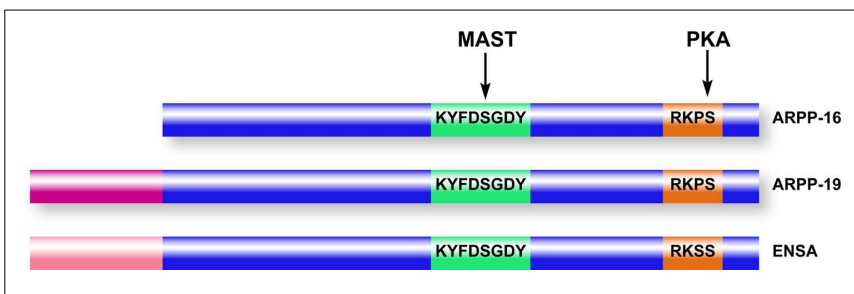

FIGURE 4 | Domain organization of ARPP-16/19/ENSA family members. ARPP-16 and ARPP-19 are generated by alternative splicing with ARPP-19 containing an additional 16 amino acids at the N-terminus. ENSA is generated from a distinct gene, and contains a 20-amino acid $\mathrm{N}$-terminal region distinct from ARPP-19. Within the conserved domains of the three proteins (blue), ARPP-16 and ARPP-19 are identical and ENSA is highly homologous. MAST kinases (or Gwl in non-mammalian systems) phosphorylate a common serine residue in a conserved central domain, while PKA phosphorylates a conserved site at the C-terminus. 
a slightly different amino acid sequence. With respect to ENSA, a similar situation occurs. The correct spliced gene is found on Chr1 and a likely pseudogene is found on Chr14 (in human).

Comparison of the various related amino acid sequences reveals that ARPP-16 represents the core structure, with the other isoforms containing additional and distinct $\mathrm{N}$ - or C-termini. ENSA differs slightly from ARPP-16 within the core structure (16 out of 96 amino acids are changed; Dulubova et al., 2001). In addition, homologs of ARPP-16/19 have been identified in Drosophila, Schistosoma mansoni, Caenorhabditis elegans, and yeast genomes. Two regions are conserved in all species, the first of which contains a motif of eight residues, KYFDSGDY, that includes a novel phosphorylation site (see further discussion below) and the second of which encompasses the site phosphorylated by PKA in mammalian species and presumably in other organisms. PKA phosphorylates ARPP-16 at Ser88 (Ser104 in ARPP-19). In mouse striatal slices, the phosphorylation of both ARPP-16 and ENSA isoforms was found to be increased following stimulation of adenylyl cyclase by forskolin (Dulubova et al., 2001). Treatment of striatal slices with a specific D1-agonist (SKF81297) also increased phosphorylation of ARPP-16 and ENSA. In contrast, treatment with a specific D2-agonist (quinpirole) decreased both the basal level and the D1-stimulated phosphorylation of both ARPP-16 and ENSA.

\section{EXPRESSION PROFILE}

Given the criteria for the protein screen that led to its discovery, enrichment of ARPP-16 in the basal ganglia was already known. Subsequent work by immunoblotting of specific brain regions and peripheral organs in addition to immunocytochemistry and in situ hybridization studies confirmed that ARPP-16 is found mainly in the striatonigral neurons in the dorsal striatum, as well as the nucleus accumbens, amygdala, and frontal cortex (Girault et al., 1990; Brene et al., 1994). Isoform-specific antibodies have been used to show that both ARPP-19 and ENSA isoforms are present in rat brain cytosol, and comigrate within the $19-\mathrm{kDa}$ region. However, ENSA is much more abundant in rodent striatum compared to ARPP-19. In contrast, ARPP-19 was found to be the major isoform in all cell lines analyzed. Since the core ARPP-16 sequence is common to all the related isoforms, there is not an antibody available that only recognizes ARPP-16. However, as expected from earlier work, ARPP-16 was detected by immunoblotting only in brain with high enrichment in the striatum. The phylogenic distribution of ARPP-16 has also been described (Girault et al., 1990). Interestingly, by immunoblotting, ARPP-16 was found in the striatum (or paleostriatum in non-mammalian eukaryotes) and frontal cortex of monkey, rat, mouse, cow, rabbit, and canary; whereas, it was not present in pigeon, amphibians, fish, or Aplysia. Immunoblotting from mouse tissue samples taken at various points in development revealed that ARPP-16 is present at its highest levels from 3 to 8 postnatal weeks when expression plateaus, whereas ARPP-19/ENSA are found at their highest level at embryonic day 16 and decline with development (Girault et al., 1990).

The molecular mechanism involved in the alternative splicing of ARPP-16 in striatal neurons is not presently known. Hyman and colleagues found that ania-6, a novel cyclin that associates with RNA polymerase II, is induced by dopamine or cocaine in the striatum (Berke et al., 2001; Nairn and Greengard, 2001). Two splice forms of ania- 6 are differentially regulated in striatal neurons in response to glutamate, dopamine, and BDNF (Sgambato et al., 2003). The regulatory pathways included both ERK and CaM kinase(s). Therefore, it is possible that regulation of expression of ARPP-16, as well as other alternatively spliced genes in striatal neurons, may be sensitive to modulation of these different intracellular pathways.

\section{POTENTIAL FUNCTIONS OF ARPP-16}

As with DARPP-32 and RCS, the initial analysis of the amino acid sequence of ARPP-16 did not reveal any obvious function. One study showed a reduction in total protein level of ARPP-19 in the temporal lobe from postmortem samples of individuals with Down's syndrome as well as reduced ARPP-19 in the cerebellum of patients with Alzheimer's disease (Kim et al., 2001). Several studies have identified possible functions for both ARPP-19 and ENSA. A role for ARPP-19 in nerve growth factor-dependent stabilization of the mRNA for growth-associated protein-43 (GAP-43) was suggested (Irwin et al., 2002). However, the specific interaction of ARPP-16 or ARPP-19 with GAP-43 mRNA has not been confirmed by follow-up studies (Andrade and Nairn, unpublished results). A role for ARPP-19, as well as ENSA, in interacting with $\alpha$-synuclein has also been suggested (Woods et al., 2007; Boettcher et al., 2008). While this interaction appears to be possible in vitro, its physiological relevance remains to be established.

ENSA was originally named after studies that identified it as a possible endogenous regulator of the $\mathrm{K}_{\mathrm{ATP}}$-coupled sulfonylurea receptor, which is targeted by the class of antidiabetic drugs, the sulfonylureas (Virsolvy-Vergine et al., 1992, 1996; Peyrollier et al., 1996). Further studies found that recombinant ENSA was able to compete with $\left[{ }^{3} \mathrm{H}\right]$-glibenclamide (a sulfonylurea) in receptor binding assays as well as to increase insulin release in MIN6 cells, a pancreatic $\beta$-cell line (Heron et al., 1998). However, it is unlikely that ENSA, a cytosolic protein, could fulfill such a role in vivo (Gros et al., 2002).

\section{REGULATION OF THE SERINE/THREONINE PROTEIN PHOSPHATASE PP2A BY ARPP-16 FAMILY MEMBERS}

The homolog of ARPP-19 in S. cerevisiae, YNL157W, has an unknown function, although reduced fitness in minimal media has been shown in null strains (Giaever et al., 2002). No significant phenotype was observed with deletion of the ARPP-19 homolog, K10C3.2, in C. elegans (Rogers et al., 2008). However, mutant ENSA in Drosophila oocytes exhibit marked meiotic maturation (Von Stetina et al., 2008). Moreover, mice null for ARPP-16/19 exhibit embryonic lethality (Horiuchi and Nairn, unpublished), suggestive of a critical function for the protein(s).

Two recent studies of mitosis in Xenopus oocytes have unexpectedly revealed a critical functional role for ARPP-19 and ENSA in control of the G2/M phase of the cell cycle (Gharbi-Ayachi et al., 2010; Mochida et al., 2010). Both of these studies were focused on indentifying substrates for a kinase, termed Greatwall $(\mathrm{Gwl})$, that was known to provide a link between Cdk1, the cyclin-dependent controller of mitosis, and the inhibition of protein phosphatase 2A (PP2A; Virshup and Kaldis, 2010). Through 
activation by Cdk1, Gwl was thought to regulate PP2A as part of a positive feed-back mechanism designed to increase the phosphorylation of mitotic substrates for Cdk1. Using proteomic screens for Gwl substrates, one study identified ARPP-19 (Gharbi-Ayachi et al., 2010), while the other identified ENSA (Mochida et al., 2010), as the major targets for Gwl in oocytes. Gwl phosphorylates the serine residue in the conserved KYFDSGDY domain (Ser62 in ARPP-19, Ser67 in ENSA, Ser46 in ARPP-16), resulting in the binding of ARPP-19 or ENSA to PP2A, and subsequent inhibition of PP2A activity.

A similar role for ARPP-19 or ENSA in regulation of mitosis in mammalian cells is implicated by preliminary studies in HeLa cells (Gharbi-Ayachi et al., 2010), and by other studies which have revealed a critical role for the mammalian homolog of $\mathrm{Gwl}$, termed microtubule-associated serine/threonine kinase-like (for MASTL) in cell cycle control (Voets and Wolthuis, 2010). Notably, biochemical studies of ARPP-16 have found that it can interact directly with the core AC dimer of PP2A (the A scaffolding and $\mathrm{C}$ catalytic subunits; Andrade et al., in preparation). Additional studies have found that Ser46 of ARPP-16 is phosphorylated to very high levels under basal conditions in striatal tissue. It is likely that the MAST3 isoform, which is related to MASTL and Gwl, phosphorylates ARPP-19 at Ser46 since this isoform is highly expressed in striatum (Garland et al., 2008). Moreover, in vitro, ARPP-16 phosphorylated by MAST kinase inhibits a number of different PP2A heterotrimeric complexes. Finally, phosphorylation of several PP2A substrates is increased in striatal tissue from conditional knockout mice in which ARPP-16 has been deleted in forebrain, including Thr75 of DARPP-32 (see Figure 3). These studies suggest that while MAST/Gwl/ARPP-16/19/ENSA signaling serves to regulate $\mathrm{PP} 2 \mathrm{~A}$ in post-mitotic neurons as well as at mitosis, the way this process is used is distinct, with PP2A being basally inhibited in MSNs, while PP2A is transiently inhibited by ARPP-19/ENSA during mitosis. MAST/ARPP-16 signaling in MSNs is also distinct from the directionality of regulation of DARPP-32 and RCS, where stimulation of PKA converts them from inactive proteins, into inhibitors of PP1, or PP2B (via CaM sequestration), respectively. The precise role of phosphorylation of ARPP-16 by PKA in terms of regulation of $\mathrm{PP} 2 \mathrm{~A}$ remains to be determined.

\section{SUMMARY AND FUTURE DIRECTIONS}

The studies of DARPP-32, RCS, and ARPP-16 over the last three decades has provided a wealth of understanding of the intracellular signaling pathways that mediate the effects of dopamine in striatal neurons. Perhaps the most striking feature of the function of these proteins is that they all act in one way or another to control the activity of three of the four major subclasses of serine/threonine protein phosphatases. Presumably, in MSNs this is a reflection of the temporal and possibly spatial requirements for intracellular signaling responding to dopamine and other neurotransmitter inputs that coordinate with dopamine action. As perhaps best exemplified by the ability of DARPP-32 to control the activation of ERK-dependent signaling at multiple levels first in the cytosol and then in the nucleus, the DARPP-32/PP1 pathway seems designed to be able to couple weak or strong inputs to specific cellular responses. In this respect, DARPP-32/PP1 may be an important component of a logical "AND gate" that serves to couple the actions of drugs abuse to coincident activation of DA and glutamate receptors and subsequently to regulation of adaptive changes in ERK signaling in the nucleus (Girault et al., 2007).

It is of interest that while DARPP-32, RCS, and ARPP-16 all act to control protein phosphatase activity they work in different ways. Both DARPP-32 and RCS are inactive until phosphorylated by PKA. DARPP-32 is a very potent direct pseudosubstrate inhibitor of PP1, while RCS works indirectly to regulate calcineurin. Phospho-ARPP-16 appears to act basally as an inhibitor of PP2A, and PKA likely modulates this action. Common to all three proteins are that they are intrinsically disordered proteins, a property that allows for great flexibility in terms of how they can interact with their targets. At least in the case of DARPP-32 and ARPP-16, they are regulated by multiple protein kinases, and thus act as regulatory hubs to integrate the actions of various neurotransmitters, and to allow for both positive and negative feedback processes to act on the regulation of the phosphatase targets.

While extensive immunocytochemical analysis has shown that all three proteins are highly expressed in MSNs, their precise localizations are not identical. For example, RCS is more highly expressed in nucleus accumbens in more rostral regions. Thus, while these three PKA targets likely function in an integrated manner in MSNs to coordinate dopaminergic signaling, they may also contribute to distinct actions of dopamine in subpopulations MSNs. While detailed studies have only been carried out for DARPP-32, it appears that all three proteins are expressed in both D1- and D2-MSNs. As a consequence, their regulation by cAMP/PKA signaling is likely to be distinct in these two major populations of striatal neurons. In D1-MSNs, increased cAMP would act to increase phosphorylation by PKA, while in D2-MSNs activation of D2 receptors would act to decrease phosphorylation by PKA. Extensive studies of DARPP-32 have identified a complex network of both positive and negative feedback processes that involve regulation of multiple sites by various kinases and phosphatases. The flexibility of these complex signaling processes may be required to allow the divergent regulation of DARPP-32 in D1- and D2-MSNs. It is also likely that DARPP-32, RCS, and ARPP-16 are themselves part of a more complex interacting signaling system, since both RCS and ARPP-16 can influence DARPP-32 phosphorylation at different sites (see Figure 3).

Despite the wealth of information concerning the regulation and function of DARPP-32, RCS, and ARPP-16, there are still outstanding questions. There is no detailed structural information about how the proteins interact with their targets, and additional $\mathrm{X}$-ray crystallography and NMR studies are required. While there is some knowledge concerning the function of PP1 in the nucleus, the precise targets for nuclear DARPP-32 remain to be identified. To date most of the functional analysis of DARPP-32, RCS, and ARPP-16 has been restricted to their actions in MSNs of striatum, but it is likely that even at lower levels of expression in other brain regions, they play important roles in neuronal signaling.

\section{ACKNOWLEDGMENTS}

We would like to thank the many colleagues and collaborators who over the last 30 years have contributed to the studies of basal 
ganglia phosphoproteins. In particular, Charles Oiumet, Atsuko Horiuchi, Jean-Antoine Girault, Akinori Nishi, Gretchen Snyder, Per Svenningsson, Allen Fienberg, James Bibb, Sergey Rakhilin, Maya Davies, Erika Andrade, Veronica Musante, James Surmeier, and Anita Aperia have made important discoveries related to the

\section{REFERENCES}

Ahn, J. H., McAvoy, T., Rakhilin, S. V., Nishi, A., Greengard, P., and Nairn, A. C. (2007a). Protein kinase A activates protein phosphatase $2 \mathrm{~A}$ by phosphorylation of the B56delta subunit. Proc. Natl. Acad. Sci. U.S.A. 104, 2979-2984.

Ahn, J. H., Sung, J. Y., McAvoy, T., Nishi, A., Janssens, V., Goris, J., Greengard, P., and Nairn, A. C. (2007b). The B'/PR72 subunit mediates $\mathrm{Ca} 2+$-dependent dephosphorylation of DARPP-32 by protein phosphatase 2A. Proc. Natl. Acad. Sci. U.S.A. 104, 9876-9881.

Albert, K. A., Hemmings, H. C. Jr., Adamo, A. I., Potkin, S. G., Akbarian, S., Sandman, C. A., Cotman, C. W., Bunney, W. E. Jr., and Greengard, P. (2002). Evidence for decreased DARPP-32 in the prefrontal cortex of patients with schizophrenia. Arch. Gen. Psychiatry 59, 705-712.

Anden, N. E., Fuxe, K., Hamberger, B., and Hokfelt, T. (1966). A quantitative study on the nigro-neostriatal dopamine neuron system in the rat. Acta Physiol. Scand. 306-312.

Baracskay, K. L., Haroutunian, V., and Meador-Woodruff, J. H. (2006). Dopamine receptor signaling molecules are altered in elderly schizophrenic cortex. Synapse 60, 271-279.

Barbano, P. E., Spivak, M., Flajolet, M., Nairn, A. C., Greengard, P., and Greengard, L. (2007). A mathematical tool for exploring the dynamics of biological networks. Proc. Natl. Acad. Sci. U.S.A. 104, 19169-19174

Bateup, H. S., Santini, E., Shen, W., Birnbaum, S., Valjent, E., Surmeier, D. J., Fisone, G., Nestler, E. J., and Greengard, P. (2010). Distinct subclasses of medium spiny neurons differentially regulate striatal motor behaviors. Proc. Natl. Acad. Sci. U.S.A. 107, 14845-14850.

Bateup, H. S., Svenningsson, P., Kuroiwa, M., Gong, S., Nishi, A., Heintz, N., and Greengard, P. (2008). Cell type-specific regulation of DARPP-32 phosphorylation by psychostimulant and antipsychotic drugs. Nat. Neurosci. 11, 932-939.

Belkhiri, A., Dar, A. A., Peng, D. F., Razvi, M. H., Rinehart, C., Arteaga, C. L., and El-Rifai, W. (2008a).
Expression of t-DARPP mediates trastuzumab resistance in breast cancer cells. Clin. Cancer Res. 14, 4564-4571.

Belkhiri, A., Dar, A. A., Zaika, A., Kelley, M., and El-Rifai, W. (2008b). tDarpp promotes cancer cell survival by up-regulation of $\mathrm{Bcl} 2$ through Akt-dependent mechanism. Cancer Res. 68, 395-403.

Benderska, N., Becker, K., Girault, J. A., Becker, C. M., Andreadis, A., and Stamm, S. (2010). DARPP-32 binds to tra2-beta1 and influences alternative splicing. Biochim. Biophys. Acta 1799, 448-453.

Berke, J. D., Sgambato, V., Zhu, P. P., Lavoie, B., Vincent, M., Krause, M., and Hyman, S. E. (2001). Dopamine and glutamate induce distinct striatal splice forms of Ania6, an RNA polymerase II-associated cyclin. Neuron 32, 277-287.

Bertran-Gonzalez, J., Hakansson, K., Borgkvist, A., Irinopoulou, T., Brami-Cherrier, K., Usiello, A., Greengard, P., Herve, D., Girault, J. A., Valjent, E., and Fisone, G. (2009). Histone $\mathrm{H} 3$ phosphorylation is under the opposite tonic control of dopamine D2 and adenosine A2A receptors in striatopallidal neurons. Neuropsychopharmacology 34, 1710-1720.

Bibb, J. A., Snyder, G. L., Nishi, A., Yan, Z., Meijer, L., Fienberg, A. A., Tsai, L. H., Kwon, Y. T., Girault, J. A., Czernik, A. J., Huganir, R. L., Hemmings, H. C. Jr., Nairn, A. C., and Greengard, P. (1999). Phosphorylation of DARPP-32 by Cdk5 modulates dopamine signalling in neurons. Nature 402, 669-671.

Bjorklund, A., and Dunnett, S. B. (2007). Fifty years of dopamine research. Trends Neurosci. 30, 185-187.

Bjorklund, A., and Lindvall, O. (1984). "Dopamine-containing systems in the CNS," in Classical Transmitters in the CNS, Part I, eds A. Bjorklund and T. Hokfelt (Amsterdam: Elsevier), 55-122.

Boettcher, J. M., Hartman, K. L. Ladror, D. T., Qi, Z., Woods, W. S., George, J. M., and Rienstra, C. M. (2008). Membrane-induced folding of the cAMP-regulated phosphoprotein endosulfine-alpha. Biochemistry 47, 12357-12364.

elucidation of the functions of DARPP-32, RCS and, ARPP- 16 . We would also like to acknowledge the generous support from the National Institute of Mental Health, the National Institute of Drug Addiction, and NARSAD, who have supported the work discussed here for many years.

Bolam, J. P., Wainer, B. H., and Smith, A. D. (1984). Characterization of cholinergic neurons in the rat neostriatum. A combination of choline acetyltransferase immunocytochemistry, Golgi-impregnation and electron microscopy. Neuroscience $12,711-718$.

Bollen, M., Peti, W., Ragusa, M. J., and Beullens, M. (2010). The extended PP1 toolkit: designed to create specificity. Trends Biochem. Sci. 35, 450-458.

Borgkvist, A., Usiello, A., Greengard, P., and Fisone, G. (2007). Activation of the cAMP/PKA/DARPP-32 signaling pathway is required for morphine psychomotor stimulation but not for morphine reward. Neuropsychopharmacology 32 1995-2003.

Brene, S., Lindefors, N., Ehrlich, M. Taubes, T., Horiuchi, A., Kopp, J., Hall, H., Sedvall, G., Greengard, P., and Persson, H. (1994). Expression of mRNAs encoding ARPP16/19, ARPP-21, and DARPP-32 in human brain tissue. J. Neurosci. 14 985-998.

Caporaso, G. L., Bibb, J. A., Snyder, G. L., Valle, C., Rakhilin, S., Fienberg, A. A., Hemmings, H. C., Nairn, A. C., and Greengard, P. (2000). Drugs of abuse modulate the phosphorylation of ARPP-21, a cyclic AMPregulated phosphoprotein enriched in the basal ganglia. Neuropharmacology 39, 1637-1644.

Clement-Cormier, Y. C., Kebabian, J W., Petzold, G. L., and Greengard, P. (1974). Dopamine-sensitive adenylate cyclase in mammalian brain: a possible site of action of antipsychotic drugs. Proc. Natl. Acad. Sci. U.S.A. 71, 1113-1117.

Clinton, S. M., Ibrahim, H. M., Frey, K. A., Davis, K. L., Haroutunian, V., and Meador-Woodruff, J. H. (2005). Dopaminergic abnormalities in select thalamic nuclei in schizophrenia: involvement of the intracellular signal integrating proteins calcyon and spinophilin. Am. J. Psychiatry 162, 1859-1871.

da Cruz e Silva, E. F., Fox, C. A., Ouimet, C. C., Gustafson, E., Watson, S. J. and Greengard, P. (1995). Differential expression of protein phosphatase 1 isoforms in mammalian brain. J. Neurosci. 15, 3375-3389.
Dancheck, B., Nairn, A. C., and Peti, W. (2008). Detailed structural characterization of unbound protein phosphatase 1 inhibitors. Biochemistry 47, 12346-12356.

Dancheck, B., Ragusa, M. J., Allaire, M., Nairn, A. C., Page, R., and Peti, W. (2011). Molecular investigations of the structure and function of the protein phosphatase 1-spinophilininhibitor 2 heterotrimeric complex. Biochemistry 50, 1238-1246.

Desdouits, F., Cheetham, J. J., Huang, H. B., Kwon, Y. G., da Cruz e Silva, E. F., Denefle, P., Ehrlich, M. E., Nairn, A. C., Greengard, P., and Girault, J. A. (1995a). Mechanism of inhibition of protein phosphatase 1 by DARPP-32: studies with recombinant DARPP-32 and synthetic peptides. Biochem. Biophys. Res. Commun. 206, 652-658.

Desdouits, F., Cohen, D., Nairn, A. C., Greengard, P., and Girault, J. A. (1995b). Phosphorylation of DARPP-32, a dopamine- and cAMPregulated phosphoprotein, by casein kinase I in vitro and in vivo. J. Biol. Chem. 270, 8772-8778.

Desdouits, F., Siciliano, J. C., Greengard, P., and Girault, J. A. (1995c) Dopamine- and cAMP-regulated phosphoprotein DARPP-32: phosphorylation of Ser-137 by casein kinase I inhibits dephosphorylation of Thr-34 by calcineurin. Proc. Natl. Acad. Sci. U.S.A. 92, 2682-2685.

Doll, B. B., Hutchison, K. E., and Frank, M. J. (2011). Dopaminergic genes predict individual differences in susceptibility to confirmation bias. $J$. Neurosci. 31, 6188-6198.

Dulubova, I., Horiuchi, A., Snyder, G. L., Girault, J. A., Czernik, A. J. Shao, L., Ramabhadran, R., Greengard, P., and Nairn, A. C. (2001). ARPP-16/ARPP-19: a highly conserved family of cAMP-regulated phosphoproteins. J. Neurochem. 77, 229-238.

Ebihara, Y., Miyamoto, M., Fukunaga, A., Kato, K., Shichinohe, T., Kawarada, Y., Kurokawa, T., Cho, Y., Murakami, S., Uehara, H., Kaneko, H., Hashimoto, H., Murakami, Y., Itoh, T., Okushiba, S., Kondo, S., and Katoh, H. (2004). DARPP-32 expression arises after a phase of dysplasia in oesophageal squamous cell carcinoma. Br. J. Cancer 91, 119-123. 
Egloff, M. P., Johnson, D. F., Moorhead, G., Cohen, P. T., Cohen, P., and Barford, D. (1997). Structural basis for the recognition of regulatory subunits by the catalytic subunit of protein phosphatase 1. EMBO J. 16, 1876-1887.

Eklof, A. C., Holtback, U., Svennilson, J., Fienberg, A., Greengard, P., and Aperia, A. (2001). Increased blood pressure and loss of anp-induced natriuresis in mice lacking DARPP32 gene. Clin. Exp. Hypertens. 23, 449-460.

El-Rifai, W., Smith, M. F. Jr., Li, G., Beckler, A., Carl, V. S., Montgomery, E., Knuutila, S., Moskaluk, C. A., Frierson, H. F. Jr., and Powell, S. M. (2002). Gastric cancers overexpress DARPP-32 and a novel isoform, $\mathrm{t}$ DARPP. Cancer Res. 62, 4061-4064.

Feldcamp, L. A., Souza, R. P., RomanoSilva, M., Kennedy, J. L., and Wong, A. H. (2008). Reduced prefrontal cortex DARPP-32 mRNA in completed suicide victims with schizophrenia. Schizophr. Res. 103, 192-200.

Fernandez, E., Schiappa, R., Girault, J. A., and Le, N. N. (2006). DARPP-32 is a robust integrator of dopamine and glutamate signals. PLoS Comput. Biol. 2, e176. doi: 10.1371/journal.pcbi.0020176

Fienberg, A. A., Hiroi, N., Mermelstein, P. G., Song, W., Snyder, G. L., Nishi, A., Cheramy, A., O'Callaghan, J. P., Miller, D. B., Cole, D. G., Corbett, R., Haile, C. N., Cooper, D. C., Onn, S. P., Grace, A. A., Ouimet, C. C., White, F. J., Hyman, S. E., Surmeier, D. J., Girault, J., Nestler, E. J., and Greengard, P. (1998). DARPP-32: regulator of the efficacy of dopaminergic neurotransmission. Science 281, 838-842.

Flavell, S. W., Cowan, C. W., Kim, T. K., Greer, P. L., Lin, Y., Paradis, S., Griffith, E. C., Hu, L. S., Chen, C., and Greenberg, M. E. (2006). Activitydependent regulation of MEF2 transcription factors suppresses excitatory synapse number. Science 311, 1008-1012.

Foster, G. A., Schultzberg, M., Hokfelt, T., Goldstein, M., Hemmings, H. C. Jr., Ouimet, C. C., Walaas, S. I., and Greengard, P. (1987). Development of a dopamine- and cyclic adenosine $\quad 3^{\prime}: 5^{\prime}$-monophosphateregulated phosphoprotein (DARPP32 ) in the prenatal rat central nervous system, and its relationship to the arrival of presumptive dopaminergic innervation. J. Neurosci. 7, 1994-2018.

Foster, G. A., Schultzberg, M., Hokfelt, T., Goldstein, M., Hemmings, H. C.
Jr., Ouimet, C. C., Walaas, S. I., and Greengard, P. (1988). Ontogeny of the dopamine and cyclic adenosine$3^{\prime}: 5^{\prime}$-monophosphate-regulated phosphoprotein (DARPP-32) in the pre- and postnatal mouse central nervous system. Int. J. Dev. Neurosci. 6, 367-386.

Frank, M. J., Doll, B. B., Oas-Terpstra, J., and Moreno, F. (2009). Prefrontal and striatal dopaminergic genes predict individual differences in exploration and exploitation. Nat. Neurosci. 12, 1062-1068.

Frank, M. J., and Fossella, J. A. (2011). Neurogenetics and pharmacology of learning, motivation, and cognition. Neuropsychopharmacology 36, 133-152.

Frank, M. J., Moustafa, A. A., Haughey, H. M., Curran, T., and Hutchison, K. E. (2007). Genetic triple dissociation reveals multiple roles for dopamine in reinforcement learning. Proc. Natl. Acad. Sci. U.S.A. 104, 16311-16316.

Garland, P., Quraishe, S., French, P., and O'Connor, V. (2008). Expression of the MAST family of serine/threonine kinases. Brain Res. 1195, 12-19.

Gharbi-Ayachi, A., Labbe, J. C., Burgess, A., Vigneron, S., Strub, J. M., Brioudes, E., Van-Dorsselaer, A., Castro, A., and Lorca, T. (2010). The substrate of Greatwall kinase, Arpp19, controls mitosis by inhibiting protein phosphatase $2 \mathrm{~A}$. Science 330, 1673-1677.

Giaever, G., Chu, A. M., Ni, L., Connelly, C., Riles, L., Veronneau, S., Dow, S., Lucau-Danila, A., Anderson, K., Andre, B., Arkin, A. P., Astromoff, A., El-Bakkoury, M., Bangham, R., Benito, R., Brachat, S., Campanaro, S., Curtiss, M., Davis, K., Deutschbauer, A., Entian, K. D., Flaherty, P., Foury, F., Garfinkel, D. J., Gerstein, M., Gotte, D., Guldener, U., Hegemann, J. H., Hempel, S., Herman, Z., Jaramillo, D. F., Kelly, D. E., Kelly, S. L., Kotter, P., LaBonte, D., Lamb, D. C., Lan, N., Liang, H., Liao, H., Liu, L., Luo, C., Lussier, M., Mao, R., Menard, P., Ooi, S. L., Revuelta, J. L., Roberts, C. J., Rose, M., RossMacdonald, P., Scherens, B., Schimmack, G., Shafer, B., Shoemaker, D. D., Sookhai-Mahadeo, S., Storms, R. K., Strathern, J. N., Valle, G., Voet, M., Volckaert, G., Wang, C. Y., Ward, T. R., Wilhelmy, J., Winzeler, E. A., Yang, Y., Yen, G., Youngman, E., Yu, K., Bussey, H., Boeke, J. D., Snyder, M., Philippsen, P., Davis, R. W., and Johnston, M. (2002). Functional profiling of the Saccharomyces cerevisiae genome. Nature 418, 387-391.

Girault, J. A., Hemmings, H. C. Jr., Williams, K. R., Nairn, A. C., and Greengard, P. (1989). Phosphorylation of DARPP-32, a dopamineand cAMP-regulated phosphoprotein, by casein kinase II. J. Biol. Chem. 264, 21748-21759.

Girault, J. A., Horiuchi, A., Gustafson, E. L., Rosen, N. L., and Greengard, P. (1990). Differential expression of ARPP-16 and ARPP-19, two highly related cAMP-regulated phosphoproteins, one of which is specifically associated with dopamineinnervated brain regions. J. Neurosci. 10, 1124-1133.

Girault, J. A., Valjent, E., Caboche, J., and Herve, D. (2007). ERK2: a logical AND gate critical for drug-induced plasticity? Curr. Opin. Pharmacol. 7, 77-85.

Glausier, J. R., Maddox, M., Hemmings, H. C. Jr. Nairn, A. C., Greengard, P., and Muly, E. C. (2010). Localization of dopamine- and cAMP-regulated phosphoprotein-32 and inhibitor1 in area 9 of Macaca mulatta prefrontal cortex. Neuroscience 167, 428-438.

Goldberg, J., Huang, H. B., Kwon, Y. G., Greengard, P., Nairn, A. C. and Kuriyan, J. (1995). Threedimensional structure of the catalytic subunit of protein serine/threonine phosphatase- 1 . Nature 376, 745-753.

Grebb, J. A., Girault, J. A., Ehrlich, M. and Greengard, P. (1990). Chronic treatment of rats with SCH-23390 or raclopride does not affect the concentrations of DARPP-32 or its mRNA in dopamine-innervated brain regions. J. Neurochem. 55, 204-207.

Greengard, P., Allen, P. B., and Nairn, A. C. (1999). Beyond the dopamine receptor: the DARPP$32 /$ protein phosphatase-1 cascade. Neuron 23, 435-447.

Gros, L., Breant, B., Duchene, B. Leroy, C., Fauconnier, G., Bataille, D., and Virsolvy, A. (2002). Localization of alpha-endosulphine in pancreatic somatostatin delta cells and expression during rat pancreas development. Diabetologia 45, 703-710.

Gu, L., Waliany, S., and Kane, S. E. (2009). Darpp-32 and its truncated variant t-Darpp have antagonistic effects on breast cancer cell growth and herceptin resistance. PLOS ONE 4, e6220. doi: 10.1371/journal.pone.0006220

Hamel, S., Bouchard, A., Ferrario, C., Hassan, S., Aguilar-Mahecha,
A., Buchanan, M., Quenneville, L., Miller, W., and Basik, M. (2010). Both t-Darpp and DARPP-32 can cause resistance to trastuzumab in breast cancer cells and are frequently expressed in primary breast cancers. Breast Cancer Res. Treat. 120, 47-57.

Hansen, C., Greengard, P., Nairn, A. C., Andersson, T., and Vogel, W. F. (2006). Phosphorylation of DARPP32 regulates breast cancer cell migration downstream of the receptor tyrosine kinase DDR1. Exp. Cell Res. 312, 4011-4018.

Hansen, C., Howlin, J., Tengholm, A., Dyachok, O., Vogel, W. F., Nairn, A. C., Greengard, P., and Andersson, T. (2009). Wnt-5a-induced phosphorylation of DARPP-32 inhibits breast cancer cell migration in a CREBdependent manner. J. Biol. Chem. 284, 27533-27543.

Heiman, M., Schaefer, A., Gong, S. Peterson, J. D., Day, M., Ramsey, K. E., Suarez-Farinas, M., Schwarz, C., Stephan, D. A., Surmeier, D. J., Greengard, P., and Heintz, N. (2008). A translational profiling approach for the molecular characterization of CNS cell types. Cell 135 , 738-748.

Hemmings, H. C. Jr., Girault, J. A., Williams, K. R., LoPresti, M. B., and Greengard, P. (1989). ARPP21, a cyclic AMP-regulated phosphoprotein $(\mathrm{Mr}=21,000)$ enriched in dopamine-innervated brain regions. Amino acid sequence of the site phosphorylated by cyclic AMP in intact cells and kinetic studies of its phosphorylation in vitro. J. Biol. Chem. 264, 7726-7733.

Hemmings, H. C. Jr., and Greengard, P. (1986). DARPP-32, a dopamine- and adenosine $3^{\prime}: 5^{\prime}$-monophosphate-regulated phosphoprotein: regional, tissue, and phylogenetic distribution. J. Neurosci. 6, 1469-1481.

Hemmings, H. C. Jr., and Greengard, P. (1989). ARPP-21, a cyclic AMP-regulated phosphoprotein enriched in dopamine-innervated brain regions. I. Purification and characterization of the protein from bovine caudate nucleus. J. Neurosci. 9, 851-864.

Hemmings, H. C. Jr., Greengard, P., Tung, H. Y., and Cohen, P. (1984a). DARPP-32, a dopamineregulated neuronal phosphoprotein, is a potent inhibitor of protein phosphatase-1. Nature 310 , 503-505.

Hemmings, H. C. Jr., Nairn, A. C., Aswad, D. W., and Greengard, P. (1984b). DARPP-32, 
a dopamine- and adenosine $3^{\prime}: 5^{\prime}$ monophosphate-regulated phosphoprotein enriched in dopamineinnervated brain regions. II. Purification and characterization of the phosphoprotein from bovine caudate nucleus. J. Neurosci. 4, 99-110.

Hemmings, H. C. Jr., Nairn, A. C., Elliott, J. I., and Greengard, P. (1990). Synthetic peptide analogs of DARPP-32 (Mr 32,000 dopamine- and cAMP-regulated phosphoprotein), an inhibitor of protein phosphatase-1. Phosphorylation, dephosphorylation, and inhibitory activity. J. Biol. Chem. 265, 20369-20376.

Hernandez-Lopez, S., Tkatch, T., PerezGarci, E., Galarraga, E., Bargas, J., Hamm, H., and Surmeier, D. J. (2000). D2 dopamine receptors in striatal medium spiny neurons reduce L-type $\mathrm{Ca} 2+$ currents and excitability via a novel PLC[beta] 1IP3-calcineurin-signaling cascade. J. Neurosci. 20, 8987-8995.

Heron, L., Virsolvy, A., Peyrollier, K., Gribble, F. M., Le, C. A., Ashcroft, F. M., and Bataille, D. (1998). Human alpha-endosulfine, a possible regulator of sulfonylureasensitive KATP channel: molecular cloning, expression and biological properties. Proc. Natl. Acad. Sci. U.S.A. 95, 8387-8391.

Hong, L., Wang, J., Zhao, Y., Han, Z., Zhou, X., Guo, W., Zhang, X., Jin, H., Wu, K., Ding, J., and Fan, D. (2007). DARPP-32 mediates multidrug resistance of gastric cancer through regulation of $\mathrm{P}$-gp and ZNRD1. Cancer Invest. 25, 699-705.

Horiuchi, A., Williams, K. R., Kurihara, T., Nairn, A. C., and Greengard, P. (1990). Purification and cDNA cloning of ARPP-16, a cAMPregulated phosphoprotein enriched in basal ganglia, and of a related phosphoprotein, ARPP-19. J. Biol. Chem. 265, 9476-9484.

Hu, J. X., Yu, L., Shi, Y. Y., Zhao, X. Z., Meng, J. W., He, G., Xu, Y. F., Feng, G. Y., and He, L. (2007). An association study between PPP1R1B gene and schizophrenia in the Chinese population. Prog. Neuropsychopharmacol. Biol. Psychiatry 31, 1303-1306.

Huang, F. L., and Glinsmann, W. (1976). A second heat-stable protein inhibitor of phosphorylase phosphatase from rabbit muscle. FEBS Lett. 62, 326-329.

Huang, H. B., Chen, Y. C., Horiuchi, A., Tsai, L. H., Liu, H. T., Chyan, C. L., Hsieh, M. J., Liu, C. K., Lin, F. M., Greengard, P., Nairn, A. C., Shiao, M.
S., and Lin, T. H. (2001). Backbone $1 \mathrm{H}, 15 \mathrm{~N}$, and $13 \mathrm{C}$ resonance assignments of ARPP-19. J. Biomol. NMR 19, 383-384.

Huang, H. B., Horiuchi, A., Goldberg, J., Greengard, P., and Nairn, A. C. (1997). Site-directed mutagenesis of amino acid residues of protein phosphatase 1 involved in catalysis and inhibitor binding. Proc. Natl. Acad. Sci. U.S.A. 94, 3530-3535.

Huang, H. B., Horiuchi, A., Watanabe, T., Shih, S. R., Tsay, H. J., Li, H. C., Greengard, P., and Nairn, A. C. (1999). Characterization of the inhibition of protein phosphatase-1 by DARPP-32 and inhibitor-2. J. Biol. Chem. 274, 7870-7878.

Irwin, N., Chao, S., Goritchenko, L., Horiuchi, A., Greengard, P., Nairn, A. C., and Benowitz, L. I. (2002). Nerve growth factor controls GAP43 mRNA stability via the phosphoprotein ARPP-19. Proc. Natl. Acad. Sci. U.S.A. 99, 12427-12431.

Ishikawa, M., Mizukami, K., Iwakiri, M., and Asada, T. (2007). Immunohistochemical and immunoblot analysis of Dopamine and cyclic AMPregulated phosphoprotein, relative molecular mass 32,000 (DARPP32 ) in the prefrontal cortex of subjects with schizophrenia and bipolar disorder. Prog. Neuropsychopharmacol. Biol. Psychiatry 31, 1177-1181.

Iversen, S. D., and Iversen, L. L. (2007). Dopamine: 50 years in perspective. Trends Neurosci. 30, 188-193.

Jin, M., Bateup, H., Padovan, J. C., Greengard, P., Nairn, A. C., and Chait, B. T. (2005). Quantitative analysis of protein phosphorylation in mouse brain by hypothesis-driven multistage mass spectrometry. Anal. Chem. 77, 7845-7851.

Kebabian, J. W., and Calne, D. B. (1979). Multiple receptors for dopamine. Nature 277, 93-96.

Kebabian, J. W., and Greengard, P. (1971). Dopamine-sensitive adenyl cyclase: possible role in synaptic transmission. Science 174, 1346-1349.

Kebabian, J. W., Petzold, G. L., and Greengard, P. (1972). Dopaminesensitive adenylate cyclase in caudate nucleus of rat brain, and its similarity to the "dopamine receptor". Proc. Natl. Acad. Sci. U.S.A. 69, 2145-2149.

Kim, S. H., Nairn, A. C., Cairns, N., and Lubec, G. (2001). Decreased levels of ARPP-19 and PKA in brains of Down syndrome and Alzheimer's disease. J. Neural Transm. Suppl. 61 263-272.
King, M. M., Huang, C. Y., Chock, P. B., Nairn, A. C., Hemmings, H. C. Jr., Chan, K. F., and Greengard, P. (1984). Mammalian brain phosphoproteins as substrates for calcineurin. J. Biol. Chem. 259, 8080-8083.

Kisielow, J., Nairn, A. C., and Karjalainen, K. (2001). TARPP, a novel protein that accompanies TCR gene rearrangement and thymocyte education. Eur. J. Immunol. 31 , 1141-1149.

Kitai, S. T., Sugimori, M., and Kocsis, J. D. (1976). Excitatory nature of dopamine in the nigro-caudate pathway. Exp. Brain Res. 24 351-363.

Kolata, S., Light, K., Wass, C. D., ColasZelin, D., Roy, D., and Matzel, L. D. (2010). A dopaminergic gene cluster in the prefrontal cortex predicts performance indicative of general intelligence in genetically heterogeneous mice. PLOS ONE 5, e14036. doi: 10.1371/journal.pone.0014036

Kunii, Y., Yabe, H., Wada, A., Yang, Q. Nishiura, K., and Niwa, S. I. (2011). Altered DARPP-32 expression in the superior temporal gyrus in schizophrenia. Prog. Neuropsychopharmacol. Biol. Psychiatry 35, 1139-1143.

Kurihara, T., Lewis, R. M., Eisler, J. and Greengard, P. (1988). Cloning of cDNA for DARPP-32, a dopamineand cyclic AMP-regulated neuronal phosphoprotein. J. Neurosci. 8 , 508-517.

Lewis, C. M., Levinson, D. F., Wise, L. H., DeLisi, L. E., Straub, R. E., Hovatta, I., Williams, N. M., Schwab, S. G., Pulver, A. E., Faraone, S. V. Brzustowicz, L. M., Kaufmann, C. A., Garver, D. L., Gurling, H. M., Lindholm, E., Coon, H., Moises, H. W., Byerley, W., Shaw, S. H., Mesen, A., Sherrington, R., O’Neill, F. A., Walsh, D., Kendler, K. S., Ekelund, J., Paunio, T., Lonnqvist, J., Peltonen, L., O’Donovan, M. C., Owen, M. J., Wildenauer, D. B., Maier, W., Nestadt, G., Blouin, J. L., Antonarakis, S. E., Mowry, B. J., Silverman, J. M., Crowe, R. R., Cloninger, C. R., Tsuang, M. T., Malaspina, D. Harkavy-Friedman, J. M., Svrakic, D. M., Bassett, A. S., Holcomb, J., Kalsi, G., McQuillin, A., Brynjolfson, J., Sigmundsson, T., Petursson, H., Jazin, E., Zoega, T., and Helgason, T. (2003). Genome scan meta-analysis of schizophrenia and bipolar disorder, part II: schizophrenia. Am. J. Hum. Genet. 73, 34-48.

Li, C. H., Liao, H. M., Hung, T. W., and Chen, C. H. (2006). Mutation analysis of DARPP-32 as a candidate gene for schizophrenia. Schizophr. Res. 87 $1-5$.

Lin, T. H., Huang, Y. C., Chin, M L., Chen, Y. C., Jeng, H. H., Lin, F. M., Shiao, M. S., Horiuchi, A., Greengard, P., Nairn, A. C., and Huang, H. B. (2004). 1H, $15 \mathrm{~N}$, and $13 \mathrm{C}$ resonance assignments of DARPP-32 (dopamine and cAMP-regulated phosphoprotein, Mr. 32,000) - a protein inhibitor of protein phosphatase-1. J. Biomol. NMR 28, 413-414.

Lindskog, M. (2008). Modelling of DARPP-32 regulation to understand intracellular signaling in psychiatric disease. Pharmacopsychiatry 41(Suppl. 1), S99-S104.

Lindskog, M., Svenningsson, P., Pozzi, L., Kim, Y., Fienberg, A. A., Bibb, J. A., Fredholm, B. B., Nairn, A. C., Greengard, P., and Fisone, G. (2002). Involvement of DARPP-32 phosphorylation in the stimulant action of caffeine. Nature 418, 774-778.

Mani, S. K., Fienberg, A. A. O'Callaghan, J. P., Snyder, G. L., Allen, P. B., Dash, P. K., Moore, A. N., Mitchell, A. J., Bibb, J., Greengard, P., and O’Malley, B. W. (2000). Requirement for DARPP-32 in progesterone-facilitated sexual receptivity in female rats and mice. Science 287, 1053-1056.

Marsh, J. A., Dancheck, B., Ragusa, M. J., Allaire, M., Forman-Kay, J. D., and Peti, W. (2010). Structural diversity in free and bound states of intrinsically disordered protein phosphatase 1 regulators. Structure 18, 1094-1103.

McAvoy, T., Zhou, M. M., Greengard, P., and Nairn, A. C. (2009). Phosphorylation of Rap1GAP, a striatally enriched protein, by protein kinase $A$ controls Rapl activity and dendritic spine morphology. Proc. Natl. Acad. Sci. U.S.A. 106, 3531-3536.

Meister, B., Askergren, J., Tunevall, G., Hemmings, H. C. Jr., and Greengard, P. (1991). Identification of a dopamine- and $3^{\prime} 5^{\prime}$-cyclic adenosine monophosphateregulated phosphoprotein of $32 \mathrm{kD}$ (DARPP-32) in parathyroid hormone-producing cells of the human parathyroid gland. J. Endocrinol. Invest. 14, 655-661.

Meister, B., Fried, G., Hokfelt, T., Hemmings, H. C. Jr., and Greengard, P. (1988). Immunohistochemical evidence for the existence of a dopamine- and cyclic AMPregulated phosphoprotein (DARPP32) in brown adipose tissue of pigs. Proc. Natl. Acad. Sci. U.S.A. 85, 8713-8716. 
Meister, B., Fryckstedt, J., Schalling, M., Cortes, R., Hokfelt, T., Aperia, A., Hemmings, H. C. Jr., Nairn, A. C., Ehrlich, M., and Greengard, P. (1989). Dopamine- and cAMPregulated phosphoprotein (DARPP32) and dopamine DAl agonistsensitive $\mathrm{Na}+, \mathrm{K}+$-ATPase in renal tubule cells. Proc. Natl. Acad. Sci. U.S.A. 86, 8068-8072.

Meyer-Lindenberg, A., Straub, R. E., Lipska, B. K., Verchinski, B. A., Goldberg, T., Callicott, J. H., Egan, M. F., Huffaker, S. S., Mattay, V. S., Kolachana, B., Kleinman, J. E., and Weinberger, D. R. (2007). Genetic evidence implicating DARPP-32 in human frontostriatal structure, function, and cognition. J. Clin. Invest. 117, 672-682.

Mittag, T., Kay, L. E., and Forman-Kay, J. D. (2010). Protein dynamics and conformational disorder in molecular recognition. J. Mol. Recognit. 23, 105-116.

Mochida, S., Maslen, S. L., Skehel, M., and Hunt, T. (2010). Greatwall phosphorylates an inhibitor of protein phosphatase $2 \mathrm{~A}$ that is essential for mitosis. Science 330, 1670-1673.

Nairn, A. C., and Greengard, P. (2001). A novel cyclin provides a link between dopamine and RNA processing. Neuron 32, 174-176.

Nairn, A. C., Hemmings, H. C. Jr., and Greengard, P. (1985). Protein kinases in the brain. Annu. Rev. Biochem. 54, 931-976.

Nakano, T., Doi, T., Yoshimoto, J., and Doya, K. (2010). A kinetic model of dopamine- and calciumdependent striatal synaptic plasticity. PLoS Comput. Biol. 6, e1000670. doi: 10.1371/journal.pcbi.1000670

Neyroz, P., Desdouits, F., Benfenati, F., Knutson, J. R., Greengard, P., and Girault, J. A. (1993). Study of the conformation of DARPP-32, a dopamine- and cAMP-regulated phosphoprotein, by fluorescence spectroscopy. J. Biol. Chem. 268, 24022-24031.

Nishi, A., Bibb, J. A., Matsuyama, S., Hamada, M., Higashi, H., Nairn, A. C., and Greengard, P. (2002). Regulation of DARPP-32 dephosphorylation at PKA- and Cdk5-sites by NMDA and AMPA receptors: distinct roles of calcineurin and protein phosphatase-2A. J. Neurochem. 81, 832-841.

Nishi, A., Bibb, J. A., Snyder, G. L., Higashi, H., Nairn, A. C., and Greengard, P. (2000). Amplification of dopaminergic signaling by a positive feedback loop. Proc. Natl. Acad. Sci. U.S.A. 97, 12840-12845.
Nishi, A., Snyder, G. L., and Greengard, P. (1997). Bidirectional regulation of DARPP-32 phosphorylation by dopamine. J. Neurosci. 17, 8147-8155.

Nishi, A., Snyder, G. L., Nairn, A. C., and Greengard, P. (1999). Role of calcineurin and protein phosphatase$2 \mathrm{~A}$ in the regulation of DARPP32 dephosphorylation in neostriatal neurons. J. Neurochem. 72, 2015-2021.

Nishi, A., Watanabe, Y., Higashi, H., Tanaka, M., Nairn, A. C., and Greengard, P. (2005). Glutamate regulation of DARPP-32 phosphorylation in neostriatal neurons involves activation of multiple signaling cascades. Proc. Natl. Acad. Sci. U.S.A. 102, 1199-1204.

Ouimet, C. C., and Greengard, P. (1990). Distribution of DARPP-32 in the basal ganglia: an electron microscopic study. J. Neurocytol. 19, 39-52.

Ouimet, C. C., Hemmings, H. C. Jr., and Greengard, P. (1989). ARPP-21, a cyclic AMP-regulated phosphoprotein enriched in dopamine-innervated brain regions. II. Immunocytochemical localization in rat brain. J. Neurosci. 9, 865-875.

Ouimet, C. C., LaMantia, A. S., Goldman-Rakic, P., Rakic, P., and Greengard, P. (1992). Immunocytochemical localization of DARPP32, a dopamine and cyclic-AMPregulated phosphoprotein, in the primate brain. J. Comp. Neurol. 323 , 209-218.

Ouimet, C. C., Langley-Gullion, K. C., and Greengard, P. (1998). Quantitative immunocytochemistry of DARPP-32-expressing neurons in the rat caudatoputamen. Brain Res. $808,8-12$.

Ouimet, C. C., Miller, P. E., Hemmings, H. C. Jr., Walaas, S. I., and Greengard, P. (1984). DARPP-32, a dopamine- and adenosine $\quad 3^{\prime}: 5^{\prime}$-monophosphateregulated phosphoprotein enriched in dopamine-innervated brain regions. III. Immunocytochemical localization. J. Neurosci. 4, 111-124.

Peyrollier, K., Heron, L., VirsolvyVergine, A., Le, C. A., and Bataille, D. (1996). Alpha endosulfine is a novel molecule, structurally related to a family of phosphoproteins. Biochem. Biophys. Res. Commun. 223, 583-586.

Pulipparacharuvil, S., Renthal, W., Hale, C. F., Taniguchi, M., Xiao, G., Kumar, A., Russo, S. J., Sikder, D., Dewey, C. M., Davis, M. M., Greengard, P., Nairn, A. C., Nestler, E. J., and
Cowan, C. W. (2008). Cocaine regulates MEF2 to control synaptic and behavioral plasticity. Neuron 59 621-633.

Ragusa, M. J., Dancheck, B., Critton, D. A., Nairn, A. C., Page, R., and Peti, W. (2010). Spinophilin directs protein phosphatase 1 specificity by blocking substrate binding sites. Nat. Struct. Mol. Biol. 17, 459-464.

Rakhilin, S. V., Olson, P. A., Nishi, A. Starkova, N. N., Fienberg, A. A., Nairn, A. C., Surmeier, D. J., and Greengard, P. (2004). A network of control mediated by regulator of calcium/calmodulin-dependent signaling. Science 306, 698-701.

Rogers, A., Antoshechkin, I., Bieri, T., Blasiar, D., Bastiani, C., Canaran, P., Chan, J., Chen, W. J., Davis, P., Fernandes, J., Fiedler, T. J., Han, M. Harris, T. W., Kishore, R., Lee, R. McKay, S., Muller, H. M., Nakamura, C., Ozersky, P., Petcherski, A., Schindelman, G., Schwarz, E. M., Spooner, W., Tuli, M. A., Van, A. K., Wang, D., Wang, X., Williams, G., Yook, K., Durbin, R., Stein, L. D., Spieth, J., and Sternberg, P. W. (2008) WormBase 2007. Nucleic Acids Res. 36, D612-D617.

Sgambato, V., Minassian, R., Nairn, A. C., and Hyman, S. E. (2003). Regulation of ania- 6 splice variants by distinct signaling pathways in striatal neurons. J. Neurochem. 86, 153-164.

Shalizi, A., Gaudilliere, B., Yuan, Z., Stegmuller, J., Shirogane, T., Ge, Q. Tan, Y., Schulman, B., Harper, J. W. and Bonni, A. (2006). A calciumregulated MEF2 sumoylation switch controls postsynaptic differentiation. Science 311, 1012-1017.

Souza, B. R., Motta, B. S., Rosa, D. V., Torres, K. C., Castro, A. A., Comim, C. M., Sampaio, A. M., Lima, F. F., Jeromin, A., Quevedo, J., and Romano-Silva, M. A. (2008). DARPP-32 and NCS-1 expression is not altered in brains of rats treated with typical or atypical antipsychotics. Neurochem. Res. 33, 533-538.

Steinbusch, H. W. (1981). Distribution of serotonin-immunoreactivity in the central nervous system of the rat-cell bodies and terminals. Neuroscience 6, 557-618.

Stipanovich, A., Valjent, E., Matamales, M., Nishi, A., Ahn, J. H., Maroteaux M., Bertran-Gonzalez, J., BramiCherrier, K., Enslen, H., Corbille, A. G., Filhol, O., Nairn, A. C., Greengard, P., Herve, D., and Girault, J. A. (2008). A phosphatase cascade by which rewarding stimuli control nucleosomal response. Nature 453 , 879-884.

Stone, R. A., Laties, A. M., Hemmings, H. C. Jr., Ouimet, C. C., and Greengard, P. (1986). DARPP32 in the ciliary epithelium of the eye: a neurotransmitter-regulated phosphoprotein of brain localizes to secretory cells. J. Histochem. Cytochem. 34, 1465-1468.

Stralfors, P., Hemmings, H. C. Jr., and Greengard, P. (1989). Inhibitors of protein phosphatase-1. Inhibitor1 of bovine adipose tissue and a dopamine- and cAMP-regulated phosphoprotein of bovine brain are identical. Eur. J. Biochem. 180, 143-148.

Surmeier, D. J., Shen, W., Day, M., Gertler, T., Chan, S., Tian, X., and Plotkin, J. L. (2010). The role of dopamine in modulating the structure and function of striatal circuits. Prog. Brain Res. 183, 149-167.

Svenningsson, P., Nairn, A. C., and Greengard, P. (2005). DARPP-32 mediates the actions of multiple drugs of abuse. AAPS J. 7, E353E360.

Svenningsson, P., Nishi, A., Fisone, G., Girault, J. A., Nairn, A. C., and Greengard, P. (2004). DARPP-32: an integrator of neurotransmission. Annu. Rev. Pharmacol. Toxicol. 44, 269-296.

Svenningsson, P., Tzavara, E. T., Carruthers, R., Rachleff, I., Wattler, S., Nehls, M., McKinzie, D. L., Fienberg, A. A., Nomikos, G. G., and Greengard, P. (2003). Diverse psychotomimetics act through a common signaling pathway. Science 302, 1412-1415.

Svenningsson, P., Tzavara, E. T., Liu, F., Fienberg, A. A., Nomikos, G. G., and Greengard, P. (2002a). DARPP-32 mediates serotonergic neurotransmission in the forebrain. Proc. Natl. Acad. Sci. U.S.A. 99, 3188-3193.

Svenningsson, P., Tzavara, E. T., Witkin, J. M., Fienberg, A. A., Nomikos, G. G., and Greengard, P. (2002b). Involvement of striatal and extrastriatal DARPP-32 in biochemical and behavioral effects of fluoxetine (Prozac). Proc. Natl. Acad. Sci. U.S.A. 99, 3182-3187.

Torres, K. C., Souza, B. R., Miranda, D. M., Nicolato, R., Neves, F. S., Barros, A. G., Dutra, W. O., Gollob, K. J., Correa, H., and RomanoSilva, M. A. (2009). The leukocytes expressing DARPP-32 are reduced in patients with schizophrenia and bipolar disorder. Prog. Neuropsychopharmacol. Biol. Psychiatry 33, 214-219. 
Tsou, K., Girault, J. A., and Greengard, P. (1993). Dopamine D1 agonist SKF 38393 increases the state of phosphorylation of ARPP-21 in substantia nigra. J. Neurochem. 60, 1043-1046.

Valjent, E., Bertran-Gonzalez, J., Herve, D., Fisone, G., and Girault, J. A. (2009). Looking BAC at striatal signaling: cell-specific analysis in new transgenic mice. Trends Neurosci. 32, 538-547.

Valjent, E., Pascoli, V., Svenningsson, P., Paul, S., Enslen, H., Corvol, J. C., Stipanovich, A., Caboche, J., Lombroso, P. J., Nairn, A. C., Greengard, P., Herve, D., and Girault, J. A. (2005). Regulation of a protein phosphatase cascade allows convergent dopamine and glutamate signals to activate ERK in the striatum. Proc. Natl. Acad. Sci. U.S.A. 102, 491-496.

Vangamudi, B., Peng, D. F., Cai, Q., El-Rifai, W., Zheng, W., and Belkhiri, A. (2010). t-DARPP regulates phosphatidylinositol-3-kinasedependent cell growth in breast cancer. Mol. Cancer 9, 240.

Varis, A., Zaika, A., Puolakkainen, P., Nagy, B., Madrigal, I., Kokkola, A., Vayrynen, A., Karkkainen, P., Moskaluk, C., El-Rifai, W., and Knuutila, S. (2004). Coamplified and overexpressed genes at ERBB2 locus in gastric cancer. Int. J. Cancer 109, 548-553.

Virshup, D. M., and Kaldis, P. (2010). Cell biology. Enforcing the Greatwall in mitosis. Science 330, 1638-1639.

Virsolvy-Vergine, A., Leray, H., Kuroki, S., Lupo, B., Dufour, M., and Bataille, D. (1992). Endosulfine, an endogenous peptidic ligand for the sulfonylurea receptor: purification and partial characterization from ovine brain. Proc. Natl. Acad. Sci. U.S.A. 89, 6629-6633.

Virsolvy-Vergine, A., Salazar, G., Sillard, R., Denoroy, L., Mutt, V., and Bataille, D. (1996). Endosulfine, endogenous ligand for the sulphonylurea receptor: isolation from porcine brain and partial structural determination of the alpha form. Diabetologia 39, 135-141.

Voets, E., and Wolthuis, R. M. (2010). MASTL is the human orthologue of Greatwall kinase that facilitates mitotic entry, anaphase and cytokinesis. Cell Cycle 9, 3591-3601.

Von Stetina, J. R., Tranguch, S., Dey, S. K., Lee, L. A., Cha, B., and Drummond-Barbosa, D. (2008). alpha-Endosulfine is a conserved protein required for oocyte meiotic maturation in Drosophila. Development 135, 3697-3706.

Walaas, I., and Fonnum, F. (1979). The effects of surgical and chemical lesions on neurotransmitter candidates in the nucleus accumbens of the rat. Neuroscience 4, 209-216.

Walaas, I., and Fonnum, F. (1980). Biochemical evidence for gammaaminobutyrate containing fibres from the nucleus accumbens to the substantia nigra and ventral tegmental area in the rat. Neuroscience 5, 63-72.

Walaas, S. I., Aswad, D. W., and Greengard, P. (1983a). A dopamineand cyclic AMP-regulated phosphoprotein enriched in dopamineinnervated brain regions. Nature 301, 69-71.

Walaas, S. I., Nairn, A. C., and Greengard, P. (1983b). Regional distribution of calcium- and cyclic adenosine $\quad 3^{\prime}: 5^{\prime}$-monophosphateregulated protein phosphorylation systems in mammalian brain. I. Particulate systems. J. Neurosci. 3, 291-301.

Walaas, S. I., Nairn, A. C., and Greengard, P. (1983c). Regional distribution of calcium- and cyclic adenosine $\quad 3^{\prime}: 5^{\prime}$-monophosphateregulated protein phosphorylation systems in mammalian brain. II. Soluble systems. J. Neurosci. 3, 302-311.

Walaas, S. I., Cala, S., and Greengard, P. (1989). Localization of ARPP-90, a major 90 kiloDalton basal ganglionenriched substrate for cyclic AMPdependent protein kinase, in striatonigral neurons in the rat brain. Brain Res. Mol. Brain Res. 5, 149-157.

Walaas, S. I., and Greengard, P. (1984). DARPP-32, a dopamine- and adenosine $\quad 3^{\prime}: 5^{\prime}$-monophosphateregulated phosphoprotein enriched in dopamine-innervated brain regions. I. Regional and cellular distribution in the rat brain. $J$. Neurosci. 4, 84-98.

Walaas, S. I., and Greengard, P. (1993). ARPP-39, a membrane-associated substrate for cyclic AMP-dependent protein kinase present in neostriatal neurons. J. Mol. Neurosci. 4, 73-88.

Walaas, S. I., and Ouimet, C. C. (1989). The ventral striatopallidal complex: an immunocytochemical analysis of medium-sized striatal neurons and striatopallidal fibers in the basal forebrain of the rat. Neuroscience 28 , 663-672.

Watanabe, T., Huang, H. B., Horiuchi, A., da Cruze Silva, E. F., HsiehWilson, L., Allen, P. B., Shenolikar, S., Greengard, P., and Nairn, A. C. (2001). Protein phosphatase 1 regulation by inhibitors and targeting subunits. Proc. Natl. Acad. Sci. U.S.A. 98, 3080-3085.

Williams, K. R., Hemmings, H. C. Jr., LoPresti, M. B., and Greengard, P. (1989). ARPP-21, a cyclic AMPregulated phosphoprotein enriched in dopamine-innervated brain regions. I. Amino acid sequence of ARPP-21B from bovine caudate nucleus. J. Neurosci. 9, 3631-3637.

Williams, K. R., Hemmings, H. C. Jr., LoPresti, M. B., Konigsberg, W. H., and Greengard, P. (1986). DARPP-32, a dopamine- and cyclic AMP-regulated neuronal phosphoprotein. Primary structure and homology with protein phosphatase inhibitor-1. J. Biol. Chem. 261, 1890-1903.

Woods, W. S., Boettcher, J. M., Zhou, D. H., Kloepper, K. D., Hartman, K. L., Ladror, D. T., Qi, Z., Rienstra, C. M., and George, J. M. (2007). Conformation-specific binding of alpha-synuclein to novel protein partners detected by phage display and NMR spectroscopy. J. Biol. Chem. 282, 34555-34567.

Yoshimi, A., Takahashi, N., Saito, S. Ito, Y., Aleksic, B., Usui, H., Kawamura, Y., Waki, Y., Yoshikawa, T., Kato, T., Iwata, N., Inada, T., Noda, Y., and Ozaki, N. (2008). Genetic analysis of the gene coding for DARPP-32 (PPP1R1B) in Japanese patients with schizophrenia or bipolar disorder. Schizophr. Res. 100, 334-341.

Zachariou, V., Sgambato-Faure, V., Sasaki, T., Svenningsson, P., Berton, O., Fienberg, A. A., Nairn, A. C., Greengard, P., and Nestler, E. J. (2006). Phosphorylation of DARPP32 at Threonine-34 is required for cocaine action. Neuropsychopharmacology 31, 555-562.

Zhan, L., Kerr, J. R., Lafuente, M. J., Maclean, A., Chibalina, M. V., Liu, B., Burke, B., Bevan, S., and Nasir, J. (2011). Altered expression and coregulation of dopamine signalling genes in schizophrenia and bipolar disorder. Neuropathol. Appl. Neurobiol. 37, 206-219.

Zhang, Y., Svenningsson, P., Picetti, R., Schlussman, S. D., Nairn, A. C., Ho, A., Greengard, P., and Kreek, M. J. (2006). Cocaine self-administration in mice is inversely related to phosphorylation at Thr34 (protein kinase A site) and Ser130 (kinase CK1 site) of DARPP-32. J. Neurosci. 26, 2645-2651.

Zhou, F. M., Wilson, C. J., and Dani, J. A. (2002). Cholinergic interneuron characteristics and nicotinic properties in the striatum. J. Neurobiol. 53, 590-605.

Conflict of Interest Statement: The authors declare that the research was conducted in the absence of any commercial or financial relationships that could be construed as a potential conflict of interest.

Received: 15 May 2011; paper pending published: 13 June 2011; accepted: 23 July 2011; published online: 26 August 2011. Citation: Walaas SI, Hemmings HC Jr., Greengard $P$ and Nairn AC (2011) Beyond the dopamine receptor: regulation and roles of serine/threonine protein phosphatases. Front. Neuroanat. 5:50. doi: 10.3389/fnana.2011.00050 Copyright (c) 2011 Walaas, Hemmings, Greengard and Nairn. This is an openaccess article subject to a non-exclusive license between the authors and Frontiers Media SA, which permits use, distribution and reproduction in other forums, provided the original authors and source are credited and other Frontiers conditions are complied with. 